\title{
Trait and state mindfulness modulate EEG microstates
}

Running title: Mindfulness modulates EEG microstates

\author{
Zarka D. ${ }^{1,2,}{ }^{*}$, Cevallos C. ${ }^{1,3}$, Ruiz P. ${ }^{3}$, Cebolla A. M. ${ }^{1}$, Petieau M. ${ }^{1}$, Bengoetxea A. ${ }^{2}$, and Cheron G. ${ }^{1,4}$ \\ ${ }^{1}$ Laboratory of Neurophysiology and Movement Biomechanics, Faculty of Motor Sciences, \\ Université Libre de Bruxelles, 1070 Brussels, Belgium \\ ${ }^{2}$ Research Unit of Osteopathy Sciences, Faculty of Motor Sciences, Université Libre de \\ Bruxelles, 1070 Brussels, Belgium \\ ${ }^{3}$ Departamento de Ingeniería Mecánica, Facultad de Ingeniería Mecánica, Escuela \\ Politécnica Nacional, Quito, Ecuador \\ ${ }^{4}$ Laboratory of Electrophysiology, Université de Mons, 7000 Mons, Belgium \\ * Correspondence: ZARKA David, david.zarka@ulb.be
}

Number of pages: 40 (whole manuscript); 31 (main text only);

Number of figures: 8; table: 2

Number of words: 248 (abstract); 118 (significance) 645 (introduction); 1503 (discussion)

\section{ACKNOWLEDGMENTS}

This work was funded by the Université Libre de Bruxelles (Belgium), the Secretaria Nacional de Ciencia y Tecnologia (Senescyt, Ecuador) and the Fonds G. Leibu. We warmly thank L. Felz, F. Bauwens, C. Maskens who kindly took part in this research as mindfulness expert, as well as to I. Kotsou for expert scientific advice. We also wish to express our gratitude to the participants of the study, as well as our thank to E. Pecoraro, E. Hortmans, E. Toussaint, and T. D'Angelo for expert administrative and technical assistance. 


\section{ABSTRACT}

Here, we aimed to characterized microstate dynamics induced by openmonitoring meditation (OM), which emphasizes a non-reactive stance toward lived experience, while participants were passively exposed to auditory stimuli. We recorded EEG signals from eighteen trained meditators before, during, and after an OM, that we compared to a matched control group at rest. To characterize brain state, we used a multidimensional-based analysis including source localization EEG microstates, phenomenological reports and personality trait questionnaires. We showed that microstate A was negatively correlated with mindfulness trait and decreased in frequency after OM compared to before in meditators. Microstate B was longer and was positively correlated to non-reactivity trait after $\mathrm{OM}$ in the meditator group. Microstate $\mathrm{C}$ was less frequent and shorter at rest before OM in meditators compared to nonmeditators, and decreased in frequency after OM in meditators. Further, the occurrence of microstate $C$ was negatively correlated to non-reactivity trait of meditators. Source localization analysis revealed that the mindfulness trait effect on microstate $C$ at rest was explained by lower activity of the salience network (identified in the anterior cingulate cortex, thalamus and insula), while the mindfulness state effect relied on a strong contribution of (anterior and posterior) cerebellum during OM. While the decreased microstate $A$ occurrence would be related to the mitigation of phonological aspect of thinking processes, the decrease of microstate $C$ occurrence would represent an index of the cognitive defusion enabled by non-reactive monitoring underlying mindfulness meditation, for which the cerebellum appears to play a crucial role. 
medRxiv preprint doi: https://doi.org/10.1101/2021.11.22.21266675; this version posted November 24, 2021. The copyright holder for this preprint (which was not certified by peer review) is the author/funder, who has granted medRxiv a license to display the preprint in perpetuity.

It is made available under a CC-BY-NC-ND 4.0 International license .

\section{SIGNIFICANCE STATEMENT}

While benefit of mindfulness meditations are extensively documented in wide range of scientific field, their neural mechanisms remain difficult to catch. Here, we characterize EEG microstate dynamics induced by open-monitoring meditation (OM) triangulated by multimodal approach including source localization, phenomenological reports and personality trait questionnaires. We found that temporal parameters of microstates related to phonological processes and mind wandering are negatively correlated to mindfulness trait and are modulated by OM. Source localization analysis revealed that the trait effect at rest was explained by lower activity of the salience network, while the state effect relied on a strong contribution of the cerebellum during $O M$. These findings suggested that EEG microstates could represent biomarkers of the cognitive effects of mindfulness. 


\section{INTRODUCTION}

Mindfulness (sati, in pali) is a central concept of Buddhism imported in Western in the late 1960s and 1970s (Bodhi, 2011). In the scientific context, mindfulness generally refers to a self-regulated attentional state focused on present moment experiences, emphasizing curiosity, openness, and acceptance (Bishop et al., 2004) and relied on attention stability and meta-awareness (Batchelor, 2011). Beyond this state characterization, mindfulness is also defined as a stable mental trait that can be developed through meditation and measured by a variety of dispositional scales (Baer et al., 2008, 2006; Brown and Ryan, 2003).

Scientific literature emphasizes four neural networks implicated in mindfulness training: the central-executive network, the default mode network (DMN), the salience network (SN) as well as the attentional networks (including dorsal and ventral pathway) (Lutz et al., 2015). Mindfulness meditation induced functional connectivity changes in widely distributed brain networks during meditation, but also at rest. In particular, resting-state functional connectivity ( $\mathrm{rSFC}$ ) studies showed that processes related to attentional control, interoception, emotion regulation and executive function were positively associated with trait mindfulness (Farb et al., 2007; Hasenkamp and Barsalou, 2012; Hölzel et al., 2013; Kilpatrick et al., 2011). In contrast, self-referential processing and mind wandering were negatively related to trait mindfulness (Bilevicius et al., 2018; Farb et al., 2007; Parkinson et al., 2019; Wang et al., 2014). Further, rsFC studies suggested that mindfulness state induced increased cognitive control over DMN functions (Brewer et al., 2011; Taren et al., 2017; Creswell et al., 2016; Zhang et al., 2021; Kral et al., 2019), uncouple sensory, affective and cognitive processing of lived experience (Grant et al., 2011) and changes the cortico-subcortical-cerebellar modulatory dynamics (Santarnecchi et al., 2021).

Large-scale neural networks dynamics at rest could also be investigated by analysis of the temporal features of EEG microstate (Lehmann et al., 1987; Koenig et al., 2002; Michel and Koenig, 2018). Microstates analysis was performed in numerous 
studies on psychiatric disorders such as schizophrenia (Rieger et al., 2016), dementia (Grieder et al., 2016), or depression (Damborská et al., 2019), but studies have also investigated microstates related to brain state not associated with diseases such as sleep (Brodbeck et al., 2012), hypnosis (Katayama et al., 2007) or meditation (Bréchet et al., 2021; Faber et al., 2017; Panda et al., 2016; Zanesco et al., 2021b).

In this context, while most of the previous mindfulness studies focused on various focus attention (FA) meditation, the present study aimed to highlight changes induced by open-monitoring meditation (OM) on microstate dynamics. Contrary to FA meditation that relies on effortful attentional control (i.e selective attention, sustained focus, monitoring, shifting attention (Hasenkamp and Barsalou, 2012)), OM requires reducing the focus on an explicit object (without loss of arousal and attentional stability) and emphasizes effortless being (i.e. openness, vigilance, monitoring, non-reactivity) (Lutz et al., 2008). This non-reactive stance enables cognitive defusion ${ }^{1}$, short-circuits and attenuates the strength of cognitive and emotional habits to favor clear reflexive awareness about the lived experience (Lutz et al., 2008).

From previous studies, we thus hypothesized that : (1) the coverage of microstate $C$ should be higher in meditators compared to non-meditators (trait effect), reflecting reduced microstate variability in meditators (Panda et al., 2016); (2) the occurrence of microstate $\mathrm{C}$ should be lower during $\mathrm{OM}$ than at rest in meditators (state effect), reflecting greater detachment to inner experience enabled by non-reactive monitoring underlying OM (Faber et al., 2017). We further expected (3) lower coverage of microstate $D$ related to less focus switching and reorientation in meditators compared to non-meditators, and during OM compared to rest (trait and state effect) (Milz et al., 2016). We also question (4) the reorganization of functional connectivity in the frontoinsular-parietal networks induced by meditation training (Bréchet et al., 2021), which could induce different microstate topographies between groups.

\footnotetext{
${ }^{1}$ Cognitive defusion is defined as the ability to gain psychological distance from internal experiences such as thoughts and feelings (Forman et al., 2012)
} 


\section{MATERIALS AND METHODS}

\section{PARTICIPANTS}

Forty volunteers were recruited during informative sessions of the standard MBSR program provided by the continuing education center of the Universite Libre de Bruxelles (ULB HELSci, Brussels, Belgium). Inclusion criteria were age between 18 and 65 years, normal hearing, no significant experience of mindfulness meditation, and no history of epilepsy, attention deficit with/without hyperactivity, or recurrent depressive episodes. Exclusion criteria were the presence of substance abuse and antecedent of psychiatric disorder. All participants provided written consent to participated after a full explanation of the investigation. This study was approved by the ethics committee of the academic hospital Erasme (Brussels, Belgium), in agreement with the Belgian law relative to research on humans (Dresse, 2005) and the Helsinki declaration (World Medical Association Declaration of Helsinki, 2013).

Among participants, 20 followed the MBSR program (MED, 10F/10M, mean age: $41.68 \pm 10.91$ years) and 20 others constituted a waitlist matched control group (noMED, $11 F / 9 M$, mean age: $43.50 \pm 15.76$ years). Participants who had engaged in the MBSR program were trained for eight weeks to FA and OM through various standard techniques such as body scan, sitting meditation, yoga, and walking meditation. The MBSR program was dispensed by senior instructors certified by the Center for Mindfulness (UMass Medical School) with more than 15 years of mindfulness teaching expertise. They followed the standard structure and content of the program (Crane et al., 2017; Kabat-Zinn, 1990) respecting the teaching assessment criteria (Crane et al., 2013). Following these standards, the training program was composed of a 3-hour intensive group session per week for 8 weeks, plus one full day (7 hours) intensive group session. Participants were further encouraged to practice at home for 45 min daily during the 8 weeks. To assess participants' commitment, they were instructed to report each day the type of exercises and the time spend to practice using a standardized table. One subject was unable to finish the training for personal reasons and was excluded from the study. Accordingly, the meantime of daily practice per participant was 23,41 
$( \pm 11,25)$ min, totalizing a mean of 52,84 hours $( \pm 11,35 \mathrm{~h})$ of practice per participant during the training.

\section{PERSONNALITY TRAIT ASSESSMENT}

Participants engaged in the MBSR program were asked to complete the French version of the Five Facets Mindfulness Questionnaire (FFMQ (Baer et al., 2006; Heeren et al., 2011)) before and after training to assess their training efficiency on mindfulness traits. The FFMQ is a commonly used assessment of trait mindfulness showing good reliability and validity (Baer et al., 2008; Carmody and Baer, 2008; de Bruin et al., 2012; Heeren et al., 2011; Soler et al., 2012). Its specificity is to be constructed as a multidimensional assessment based on five previous scales allowing to characterize mindfulness according to five sub-facets: observing, non-reactivity to inner experience, non-judgment, describing, and acting with awareness (Baer et al., 2008, 2006). FFMQ is responsive to various forms of mindfulness training (Khoury et al., 2013) as well as to the amount and quality of mindfulness practice (Goldberg et al., 2014). Pre- versus posttraining comparison showed that FFMQ scores were significantly increased after the 8week training (paired t-test, FFMQ: $t=4.372, p<0.001$; observing: $t=2.929, p=0.010$; describing: $t=3.528, p=0.003$; non-reactivity: $t=0.331, p=0.745$; non-judgement: $t=$ 4.737, $\mathrm{p}<0.001$; Acting with awareness: $\mathrm{t}=3.378, \mathrm{p}$ 0.004). To allow traits comparison between groups, wait-list participants were also asked to complete the FFMQ before experiments. Moreover, all participants were asked to complete the Hospital Anxiety and Depression Scale (HADS, (Zigmond and Snaith, 1983)) to assess their tendency to anxiety and depression, as well as the Pittsburgh Sleep Quality Index (PSQI, (Buysse et al., 1989)) and Perceived Stress Scale (PSS, (Cohen et al., 1983; Nielsen et al., 2016)) to control potential confounding effects related to sleep quality and stress level between groups.

\section{RECORDING CONDITIONS}

Experiments take place in the Laboratory of Neurophysiology and Movement Biomechanics (ULB) at Brussels, Belgium. The EEG session was divided into three 
successive eyes-closed recording blocks. The first block (RS1) corresponded to restingstate recordings for 8 minutes for both groups. They were instructed to keep their eyes closed, motionless, and wait for the recording to end. They were invited to stay awake and to take advantage of this time to think about their daily life concern. To stimulate self-referenced thought and mind wandering (MW) during this block, light ecological semi-structured exchange oriented to daily life concerns was performed during installation (supplementary material). The second block (RS2/OM) consists of a 24minutes continuous mindfulness meditation recording for meditators and resting-state recording for non-meditators. To facilitate OM, this block was subdivided into three periods of 8 minutes according to meditation steps classically followed during the training program. The first 8-min period consisted of breath-focused meditation to promote calm and stability of attention. The next 8-min period consisted of bodyfocused meditation, where participants were instructed to open the attentional focus and progressively include whole-body sensations, emotions, and thoughts. The last 8min period consisted of OM, where participants were instructed to open the scope to the experiential field letting phenomena spontaneously arise into the awareness field in a non-reactive stance. The meditation was not guided but transitions between periods were orally provided by an experimenter using specific sentences. In contrast, nonmeditators were instructed to not care of sentences provided orally and to wait in the same way as in the first block. They were invited to stay awake and if needed to actively nourish their thoughts. The last block (RS3) corresponded to a new 8 min-period of resting-state recordings for both groups, with similar instructions to the first block.

\section{PHENOMENOLOGICAL ASSESSMENT}

The three blocks were designed as minimal auditory oddball protocol, where participants were instructed to not pay attention to auditory stimuli. Auditory stimuli (540/440Hz, 80 dB, 101 ms duration, ISI: 3s) were presented via loudspeakers bilaterally placed behind the subject. To avoid the surprise effect, participants were exposed to the stimuli for 1 min before recordings. Event-related data from passive oddball are subject to another research article. At the end of each block, participants were asked to rate the 
8-last minutes on a 5-point Likert scale ( 1 = not present at all; 5 = extremely present) about their level of sleepiness, mind wandering, auditory distractibility, bodily discomfort, and emotional charge (positive or negative indifferently). Questions were formulated as "Please rate how tired you were" according to Brandemeyer et al. (2018) methods (see supplementary material). Ratings were then completed by short structured interviews adapted from Petitmengin et al. (2019) methods, oriented on the description of their experience according to each phenomenal aspect. Reports were compared with standardized criteria-based scale to refined rating across participants (see supplementary material). To avoid bias, the experimenter performing the interviews was blinded regarding groups.

\section{EEG RECORDING AND PREPROCESSING}

EEG recordings were made using an ASA system (ANT software, the Netherlands) with $128 \mathrm{Ag} / \mathrm{AgCl}$ sintered ring electrodes embedded in an active-shield cap (10-20 system) and shielded co-axial cables. Eye movements were recorded using two bipolar electrodes: one placed horizontally on each outer eye canthus, the other placed vertically above and below the right eye. All electrodes were referred to the ears lobes. The ground electrode was placed in the neck on the $\mathrm{C} 7$ spinous process. Impedances were kept below $10 \mathrm{k} \Omega$ and checked before each block recording. Signals were recorded with a sampling rate of $2048 \mathrm{~Hz}$ and a resolution of 16 bits. We used EEGLAB software (Delorme and Makeig, 2004) for off-line data treatment. Data were band-pass filtered between 1 and $40 \mathrm{~Hz}$. Filtered EEG was downsampled to $125 \mathrm{~Hz}$. Noisy electrodes (max 10\%) were interpolated using three-dimensional spherical splines. Cleaned EEG was rereferenced to the average reference. EEG data was reduced to 110 channels to remove muscular artifacts originating in the neck and face. Six minutes of continuous EEG data per block were selected for the analysis. At this stage, data from three subjects (1 MED, 2 CTRL) were rejected due to large artifacts probably related to drowsiness. The final analysis concerns 36 subjects (18 MED, 10F/9M, mean age: $42.39 \pm 10.78$ years; 18 noMED, $10 \mathrm{~F} / 8 \mathrm{M}$, mean age: $43.22 \pm 16.02$ years) 


\section{MICROSTATES ANALYSIS}

Microstate analysis was performed with freely available Cartool Software 3.70 (Brunet et al., 2011). Following standard procedures (Michel and Koenig, 2018), we used k-means clustering to estimate the set of topographies explaining the EEG signals for each participant and each condition. Only data points at local maximum GFP (global field power) were considered for clustering to improve the signal-to-noise ratio. The polarity of the maps was ignored. The cluster map of each participant was then subjected to a second k-means cluster analysis across participants. To distinguish trait difference between groups and state difference between conditions, we performed two streams of analysis: trait and state analysis respectively (see below). For each clustering of these two analyses, we calculated the GEV (global explained variance) as the sum of the microstates explained variance (weighted by the GFP at each moment in time) to assess the representativeness of microstates topographies in regards to the original EEG data. We then calculated the duration, occurrence, and coverage of each microstate for each participant and condition (Michel and Koenig, 2018).

To investigate the trait effect between groups, we first applied the second $k$ means clustering on data at rest before meditation (RS1) across all participants (meditators and non-meditators) accordingly to Damborksa et al. (Damborská et al., 2019) methods. We used six independent optimization criteria merged in a single metacriterion to determine the optimal number of clusters (Bréchet et al., 2019; Krzanowski and Lai, 1988; Malika et al., 2014; Milligan and Cooper, 1985). The best topographic configuration of all participants at rest was calculated by spatial correlations between every map identified at the global level and the individual participant's topographical map at each data point of the original recording. Thus, the GFP-normalized map at each time point of the participant's original EEG was labeled with the microstate map with the highest correlation (ignoring polarity). To avoid artificially interrupt temporal segments of stable topography by noise during low GFP, we used a sliding window (half size $=3$; Besag factor $=10$, (Brunet et al., 2011)). The $k$ means clustering determined that the optimal number of microstates was four 
explaining $70.18 \%$ of the global variance. The four maps corresponded to the classical microstates labeled as A, B, C, and D in literature (Figure 1).

To investigated the state effect on microstate topographies and temporal parameters, we applied the second $k$-means clustering across participants per conditions (RS1, RS2/OM, RS3) accordingly to Bréchet al. (Bréchet et al., 2021). Giving the four microstates determined by previous trait analysis, we fixed the number of clusters to four for each condition and group clustering. This allowed us to compare state microstates between conditions, but also to compare microstates related to the trait analysis with these related to the state analysis, and to compare the microstate maps with these of previous studies. Here too, each time point was assigned to the microstate class of the highest correlation (ignoring polarity). The four mean maps per participant were obtained by averaging all time points with the same label. GEV of each microstate clustering explained around $70 \%$ of the data per conditions and groups (MED: RS1: 72.2\%, OM: 71.5\%, RS3: 72.4\%; noMED: RS1: 66.7\%, RS2: 66.9\%, RS3: 68.3\%).

As illustrated in Figure 1, microstate maps were highly similar across conditions in meditators and corresponded to canonical microstates labeled A, B, C, and D in the literature. Spatial correlation between conditions showed very strong correlations for each map (mean per map: $96.2 \pm 2.4 \%$ ). In contrast, non-meditators identified three maps that corresponded to canonical microstates $A, B$, and $D$ and one other less consistent in regards to canonical microstate $\mathrm{C}$, in particular for RS1 and RS2 conditions (Figure 1). Spatial correlation between conditions showed strong correlation for B-like $(96.5 \pm 1.5 \%)$ and $D$-like maps $(97.9 \pm 1.3 \%)$, and weaker for two other maps (A: 85,7 $\pm 12.3 \%$; C: $79.3 \pm 4.5 \%)$. Spatial correlation between group showed strong correlations between conditions for A-like map (94.8 $\pm 6.6 \%)$, B-like map (97.7 $\pm 1.4 \%)$ and D-like map $(96.6 \pm 2.7 \%)$, and a weaker correlation for the last map (69.1 $\pm 24.0 \%)$, in particular for RS1 (69.1\%) and RS2 (45.1\%) conditions (RS3: 93.1\%). For simplicity and accordingly to these spatial correlations analysis, we labeled these four maps as $A, B$, « $C$ » and D across conditions in both groups (Figure 1). 
medRxiv preprint doi: https://doi.org/10.1101/2021.11.22.21266675; this version posted November 24, 2021. The copyright holder for this preprint (which was not certified by peer review) is the author/funder, who has granted medRxiv a license to display the preprint in perpetuity.

It is made available under a CC-BY-NC-ND 4.0 International license .

A CLUSTERING of voltage map from EEG signals

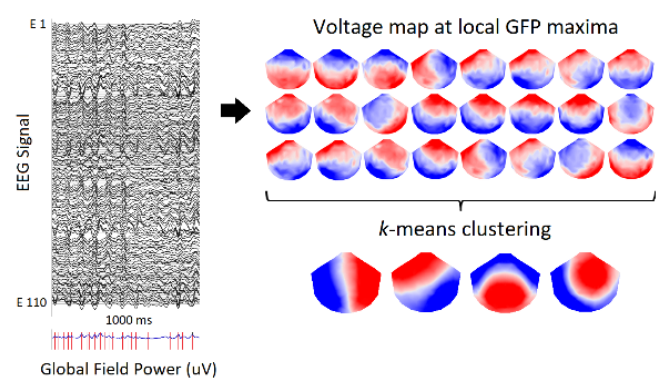

C TRAIT ANALYSIS
B LABELING of EEG signals with microstate

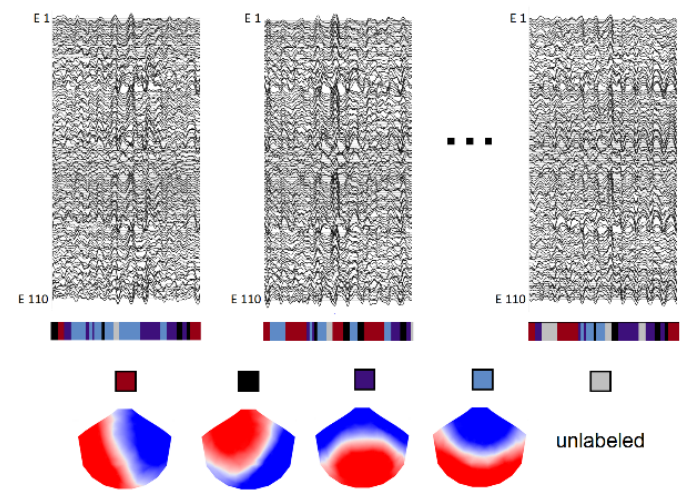

RS1

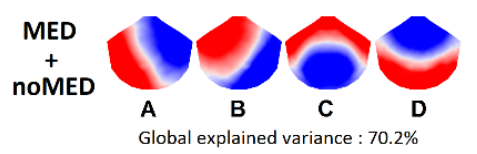

D STATE ANALYSIS

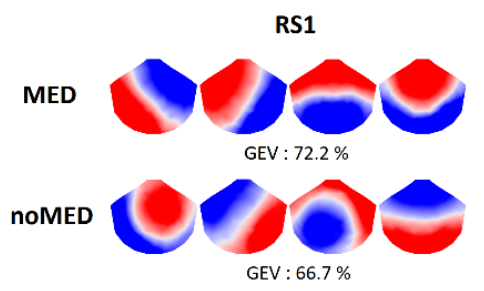

A

B $\quad C$ D $D$

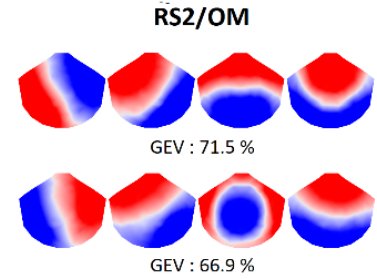

A

B " C » D

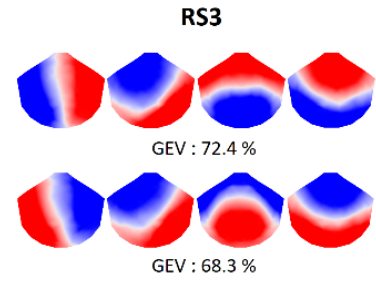

A

B «C $»$ D

Figure 1: Microstate analysis method. (A) Eyes-closed EEG signals from 110 electrodes. Voltage maps at local GFP peaks are identified as periods of topographic quasi-stability. A first $K$-means clustering determined the subjects-level clusters from voltage maps at local GFP peaks; (B) After a second $k$-means clustering identifying global clusters from subjects-level microstates, the original EEG signals from each recording are continuously labeled with the best-correlated global microstate map. The occurrence, duration, and coverage for all microstates were calculated from these labeled EEG recording; (C) Set of four cluster maps best explaining the data as revealed by $k$-means clustering across all subjects (meditators and non-meditators) at first 8-min eyes closed recording (RS1); (D) Set of four cluster maps identified by fixed 4-means clustering explaining the data according to groups (Med, noMED) and successive mental states (RS1, RS2/OM, RS3). Note that microstate labeled " C " showed different topographies between conditions within non-meditators (mean spatial correlation: $79.3 \pm 4.5 \%$ ) and between groups in RS1 (69.1\%) and RS2 (45.1\%). 


\section{SOURCE ANALYSIS}

According to distinctive microstate " $\mathrm{C}$ » maps related to RS1 and RS2 in nonmeditators, we investigated generators underlying topographical dissimilarities of microstate " $C$ » between groups and conditions through standardized weighted lowresolution electromagnetic tomography analysis (swLORETA, ASA Software, ANT Neuro, the Netherlands) (Cebolla et al., 2017, 2016, 2011; Leroy et al., 2017; Palmero-Soler et al., 2007; Zarka et al., 2021, 2020). Derived from the sLORETA method (Pascual-Marqui, 2002; Pascual-Marqui et al., 2002; Wagner et al., 2004), swLORETA model spatially distinct sources of neuronal activity from EEG signals without prior knowledge about the anatomical location of the generators even when two dipoles are simultaneously active, and permits the reconstruction of surface and deep sources incorporating a singular value decomposition-based lead field weighting the varying sensitivity of the sensors to current sources at different depths (Cebolla et al., 2016, 2011; Palmero-Soler et al., 2007).

To estimate microstate sources, we characterized the generators of each microstate per participant and condition by applying swLORETA methods on $50 \mathrm{~ms}$ periods showing the best spatial correlation with the given microstate. Following standards, the current density of every voxel was divided by the mean current density value of all voxels for every participant and condition. This gave us a normalized inverse solution in which a voxel value greater than 1 indicates greater activity than the mean. We then calculated the average of such normalized inverse solution in each condition for both groups. To compare groups and conditions, we created an image resulting from subtracting the modulus of the swLORETA solution of one group or condition to the modulus of the swLORETA solution of compared group or condition.

The swLORETA solution was obtained using a 3D grid of 2030 points (or voxels) that represented possible sources of the signal. Based on the probabilistic brain tissue maps provided by the Montreal Neurological Institute (Collins et al., 1994), the solution was restricted to the gray matter and cerebellum. The 2030 grid points $(10.00 \mathrm{~mm}$ grid 
spacing) and recording array (128 electrodes) were indexed by the Collins $27 \mathrm{MRI}$ produced by the MNI (Evans et al., 1993). The Boundary Element Model was used to solve the forward problem (Geselowitz, 1967). The final coordinates (x,y,z, Talairach coordinates) were obtained using ASA software and identified as Brodmann areas based on the Talairach atlas (Lancaster et al., 2000).

\section{STATISTICAL ANALYSIS}

To investigate associations between personality traits, lived experience, and microstate dynamics, we calculated Spearman's rank correlation coefficients between each microstate temporal parameter, scores related to phenomenological reports, and questionnaires (and subscales). In accordance with the microstate clustering methods applied, the correlation analysis related to trait analysis was performed across all participants (meditators and non-meditators at RS1), while these related to state analysis were specific to each group and conditions. Considering the close relationship between mindfulness trait and state, we used FFMQ as both a measure of mindfulness trait (trait analysis) but also as an indicator characterizing mental state during meditation practice (state analysis). We also take into account the amount and regularity of practice during the 8-week training program in meditators.

Between-group comparisons related to trait analysis were performed by independent t-tests for questionnaires (FFMQ, HADS, PSS, PSQI) and temporal parameters (duration, occurrence, and coverage) of each global microstate identified by first k-means clustering. We applied the false discovery rate method provided by Cartool Software to correct statistics for multiple comparisons (Benjamini and Hochberg, 1995; Lindquist and Mejia, 2015). Regarding state analysis, phenomenological reports were analyzed through Kendall's $W$ and Mann-Whitney $U$ tests for condition and group comparisons. Considering that temporal parameters can be compared only if microstates between conditions have the same topography (Bréchet et al., 2021; Grieder et al., 2016), the distinctive microstate « C » maps related to RS1 and RS2 in nonmeditators did not allow us to compare microstate between conditions within the non- 
meditator group, nor between groups. Nevertheless, we performed a repeated measure ANOVA to compare microstate temporal parameters between mental state (RS1, OM, RS2) within the meditator group. If needed, sphericity violations were corrected by Greenhouse-Geisser correction. Holms corrected paired $t$-tests were used as posthoc tests.

For source analysis, the statistical differences between conditions were determined by non-parametric corrected permutations as proposed by Nichols et al. (Nichols and Holmes, 2002) which uses the data itself to generate the probability distribution for testing against the null hypothesis and controls for the false positives that may result from performing multiple hypothesis tests (Nichols and Holmes, 2002). To perform the permutation, we used the $t$-test as the value of merit. We compute Timage ( $T$ value per voxel) by performing a one-sample t-test (one-tailed) for each voxel of the source space. The null hypothesis is that the distribution of the voxel values of the difference images had a bigger mean in one group/condition than the other (and inversely). Instead of assuming a normal distribution to assess the statistical significance of the T score at each voxel, we used the permutation method to create an empirical distribution as explained in detail by Cebolla et al. (Cebolla et al., 2011). The Holmes maximal correction was calculated separately for each comparison between groups and conditions. The 95th percentile of the permutation distribution was used for the corrected maximal statistics which defines the 0.05 level of the corrected significance threshold. Thus, we rejected the null hypothesis for voxel of the unpermuted T-image with $t$-values greater than the $95^{\text {th }}$ percentile of the permutation distribution of the corrected maximal statistics (Holmes et al., 1996). 


\section{RESULTS}

\section{TRAIT analysis}

\section{Correlation analysis}

Spearman's rank correlation highlighted that FFMQ was negatively correlated to $\operatorname{PSS}(\rho(34)=-0.607, p<0.001)$ and $\operatorname{HAD}(\rho(34)=-0.705, p<0.001)$, which were positively correlated each other $(\rho(34)=0.736, p<0.001)$ across participants. We also found a positive association between depression score and emotional charge across participants (HAD: $\rho(34)=0.360, p=0.034$; anxiety: $\rho(34)=0.239, p=0.167$; depression $: \rho(34)=$ $0.417, p=0.013)$. FFMQ and PSS were correlated to sleepiness, negatively and positively respectively $(\rho(34)=-0.543, p<0.001 ; \rho(34)=0.489, p=0.003)$.

Non-reactivity sub facet of FFMQ was negatively correlated with temporal parameters of microstate $C$ across participants (occurrence: $\rho(34)=-0.325, p=0.057$; duration: $\rho(34)=-0.357, p=0.035$; coverage: $\rho(34)=-0.352, p=0.038$ ). Besides, observing sub facet of FFMQ was negatively correlated with both auditory distractibility $(\rho(34)=-0.375, p=0.026)$ and the duration of microstate $C(\rho(34)=-0.388, p=0.021)$ across participants. The duration of microstate $\mathrm{C}$ was also correlated with auditory distractibility across participants, but positively as illustrated in Figure $2(\rho(34)=0.465$, $p=0.004)$.

We also found that FFMQ total score was negatively associated with the occurrence and the coverage of microstate A across participants (respectively: $\rho(34)=$ $0.363, p=0.032 ; \rho(34)=-0.335, p=0.49$; Figure 3). These correlations were carried by non-reactivity (respectively: $\rho(34)=-0.333, p=0.051 ; \rho(34)=-0.325, p=0.057$ ) and nonjudgment (respectively: $\rho(34)=-0.374, p=0.027 ; \rho(34)=-0.420, p=0.012$ ) subfacets of FFMQ. Non-judgment subfacet of FFMQ was also positively correlated with regularity of daily practice in meditators $(\rho(18)=0.534, p=0.027)$. 
A

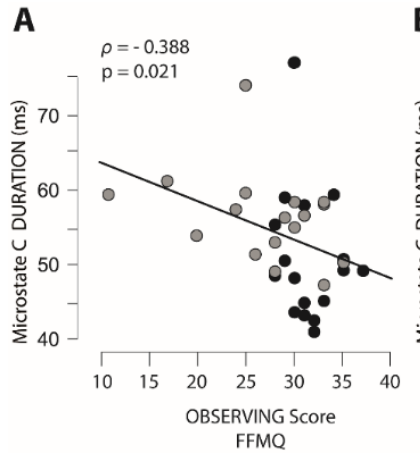

B

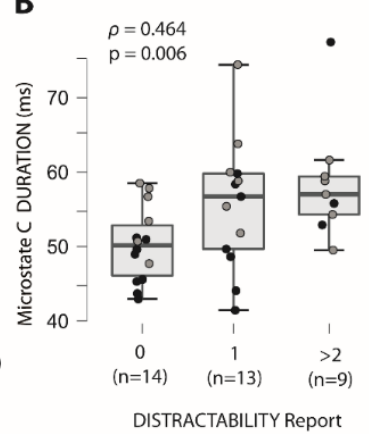

C

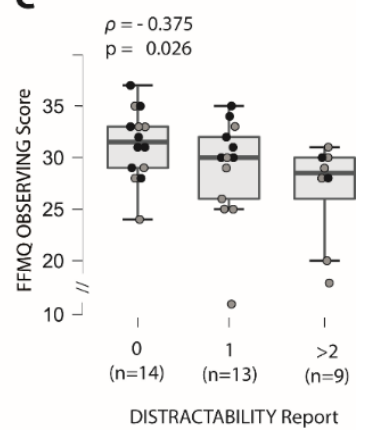

Figure 2: Correlations between microstate C temporal parameters, trait mindfulness, and phenomenological reports across all participants. We found that $(A)$ duration of microstate $C$ was negatively correlated to observing sub facets score of FFMQ. Further, (B) duration of microstate C durations was positively correlated to auditory distractibility, while (C) observing sub facets scores were negatively associated with auditory distractibility reports. Note that duration of microstate $\mathrm{C}$ were significantly different according to distractibility report $(F(2,33)=3.961, p=0.029)$, in particular between 0 and $>2$ scores $(t=-2.717, p=0.031)$. In accordance with the microstate clustering method including all participants (meditators and non-meditators), correlations were also performed across participants of both groups. Meditators (black dots) and non-meditators (grey dots) were indicated for information only.
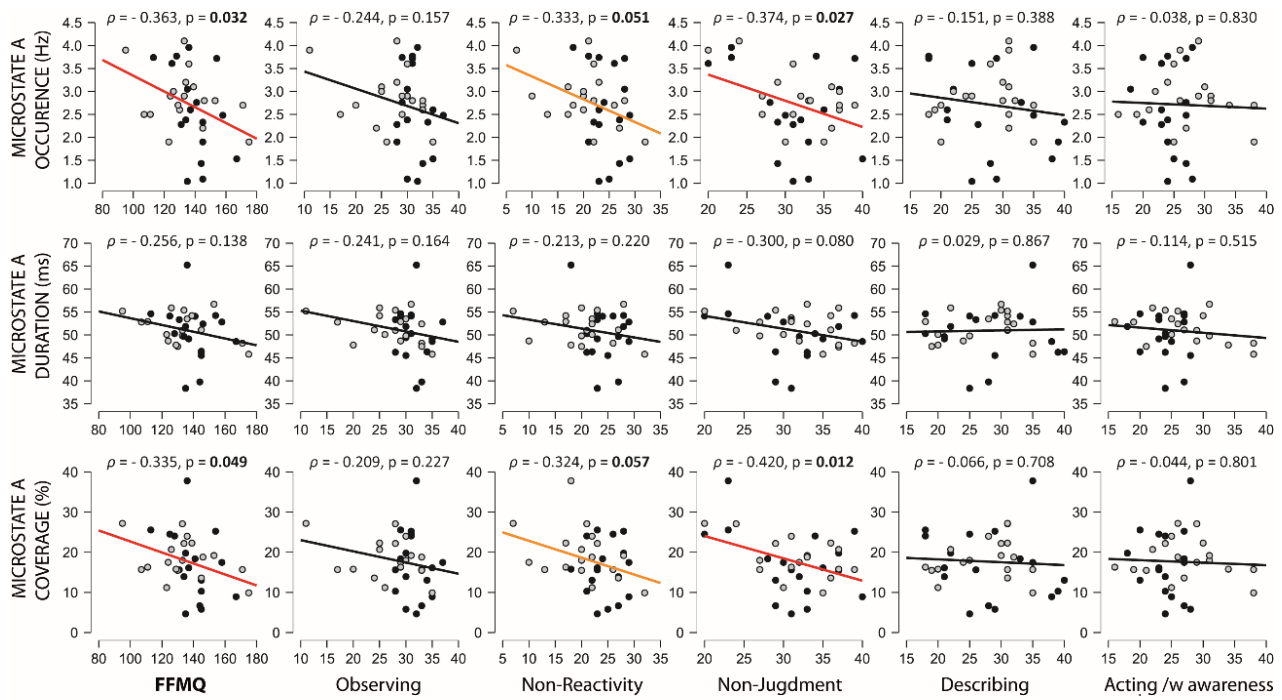

Figure 3: Correlations between FFMQ total scores and temporal parameters of microstate at the first 8minute eyes closed rest recording, across all participants. Trends and significant correlations are marked by orange and red lines respectively. Meditators (black dots) and non-meditators (grey dots) are distinguished for information only. 


\section{Between-group analysis}

Although no group difference was highlighted for trait mindfulness global score (FFMQ: $t(34)=0.996, p=0.326)$, we observed that meditators showed significant higher scores related to observing (MED: $31.47 \pm 2.60$, CTRL: $27.06 \pm 6.13 ; t(34)=2.744, p=$ 0.010 ) and non-reactivity to inner experience (MED: $24.53 \pm 3.18$, CTRL: $20.28 \pm 6.20$; $t(34)=2.528, p=0.016$ ) subfacets compared to non-meditators (Table 1). Other subfacets (describing, non-judgment and acting with awareness) did not showed significant difference between groups (all $t<2.00, p>0.05$ ). Also, meditators and nonmeditators did not differ for sleep quality (PSQI: $t(34)=-0.054, p=0.958$ ), perceived stress (PSS: $t(34)=-1.007, p=0.321$ ) as well as anxiety and depression scores (HAD: $t(34)$ $=-0.348, p=0.348$; Anxiety: $t(34)=-0.639, p=0.527$; Depression: $t(34)=-0.907, p=$ $0.371)$.

Regarding microstates, meditators showed lower occurrence, duration, and coverage of microstate $C$ compared to non-meditators (respectively: $t(34)=2.16, p=$ $0.038 ; t(34)=2.34, p=0.025 ; t(34)=2.17, p=0.037 ;$ Table 1). No significant difference relative to temporal parameters of microstate $A, B$ and $D$ were found (all $t<2.00, p\rangle$ 0.05). While groups did not differ in regards to mind wandering, auditory distractibility, bodily discomfort and sleepiness, participant's reports indicated that meditators showed lower emotional charge than non-meditators $(z=-3.080, p=0.004)$ during the first 8-min eyes-closed resting state recording. 
medRxiv preprint doi: https://doi.org/10.1101/2021.11.22.21266675; this version posted November 24, 2021. The copyright holder for this preprint (which was not certified by peer review) is the author/funder, who has granted medRxiv a license to display the preprint in perpetuity.

It is made available under a CC-BY-NC-ND 4.0 International license .

Table 1: Trait Analysis. Questionnaires scores, microstate temporal parameters, and related statistics between groups.

\begin{tabular}{|c|c|c|c|c|c|c|c|}
\hline & \multicolumn{2}{|c|}{$\begin{array}{l}\text { MED } \\
\mathbf{N}=18\end{array}$} & \multicolumn{2}{|c|}{$\begin{array}{l}\text { noMED } \\
N=18\end{array}$} & \multicolumn{3}{|c|}{$\begin{array}{c}\text { Statistics } \\
\text { Between Groups }\end{array}$} \\
\hline & MEAN & SD & MEAN & SD & $t$ & $p$ & sig \\
\hline PSQI & 5.17 & 2.43 & 5.22 & 3.67 & -0.054 & 0.958 & ns. \\
\hline PSS & 22.41 & 5.43 & 24.33 & 5.83 & -1.007 & 0.321 & ns. \\
\hline HADS & 9.65 & 3.89 & 11.06 & 4.78 & -0.953 & 0.348 & ns. \\
\hline Anxiety & 6.41 & 2.69 & 7.06 & 3.23 & -0.639 & 0.527 & ns. \\
\hline Depression & 3.24 & 1.86 & 4.00 & 2.97 & -0.907 & 0.371 & ns. \\
\hline FFMQ & 139.59 & 12.82 & 133.89 & 20.02 & 0.996 & 0.326 & ns. \\
\hline Observing & 31.47 & 2.60 & 27.06 & 6.13 & 2.800 & 0.010 & $* *$ \\
\hline Non-Reacting & 24.53 & 3.18 & 20.29 & 6.20 & 2.528 & 0.016 & $*$ \\
\hline Non-Judgment & 31.00 & 5.49 & 31.89 & 5.86 & 0.497 & 0.622 & ns. \\
\hline Describing & 28.35 & 7.26 & 27.39 & 5.59 & 0.442 & 0.662 & ns. \\
\hline Acting w/ awareness & 24.24 & 2.95 & 27.29 & 5.96 & -1.930 & 0.065 & ns. \\
\hline \multicolumn{8}{|l|}{ MICROSTATE A } \\
\hline Occurrence & 2.56 & 0.94 & 2.85 & 0.60 & -1.109 & 0.275 & ns. \\
\hline Duration & 50.17 & 6.03 & 51.61 & 3.23 & -0.896 & 0.376 & ns \\
\hline Coverage & 16.81 & 8.46 & 18.38 & 4.86 & -0.682 & 0.500 & ns \\
\hline \multicolumn{8}{|l|}{ MICROSTATE B } \\
\hline Occurrence & 3.18 & 0.86 & 3.12 & 0.62 & 0.275 & 0.822 & ns. \\
\hline Duration & 57.06 & 14.55 & 54.86 & 9.68 & 0.532 & 0.598 & ns. \\
\hline Coverage & 24.86 & 14.32 & 22.80 & 11.17 & 0.479 & 0.635 & ns. \\
\hline \multicolumn{8}{|l|}{ MICROSTATE C } \\
\hline Occurrence & 2.69 & 0.70 & 3.17 & 0.62 & -2.161 & 0.038 & $*$ \\
\hline Duration & 51.28 & 8.48 & 56.97 & 5.88 & -2.341 & 0.025 & $*$ \\
\hline Coverage & 18.00 & 7.99 & 23.69 & 7.72 & -2.174 & 0.037 & $*$ \\
\hline \multicolumn{8}{|l|}{ MICROSTATE D } \\
\hline Occurrence & 3.87 & 0.60 & 3.90 & 0.99 & 0.098 & 0.922 & ns. \\
\hline Duration & 73.90 & 26.22 & 65.76 & 12.04 & 1.196 & 0.240 & ns. \\
\hline Coverage & 40.34 & 16.12 & 35.13 & 0.97 & 1.073 & 0.291 & ns. \\
\hline
\end{tabular}




\section{STATE Analysis}

\section{Phenomenological analysis}

Phenomenological reports indicated moderate to very low mind wandering and auditory distractibility (means per condition $<2.5$ ) according to groups and conditions (Figure 4, Table 2). Reports from non-meditators showed no condition effect on mind wandering and auditory distractibility (both $X^{2}<0.130, p>0.937$ ). In contrast, meditators reported lower mind wandering during RS2/OM compared to two other conditions $\left(X^{2}=13.298, p<0.001 ; \mathrm{RS} 1: z=-2.808, p=0.005 ; \mathrm{RS} 3: z=-2.767, p=0.006\right)$, suggesting a successful commitment in meditation practice. They also reported lower auditory distractibility during RS3 compared to RS1 ( $X^{2}=8.600, p=0.014 ; z=-3.000, p$ $=0.003)$. Group comparison showed also that meditators reported lower mind wandering during RS2/OM (RS2: $z=-3.616, p<0.001)$, as well as lower auditory distractibility during RS2/OM and RS3 (RS2/OM: $z=-1.991 p=0.46 ; R S 3: z=-2.785 p=$ 0.010) compared to non-meditators.

Regarding other phenomenal aspects controlled, reports indicated low to very low emotional charge, physical discomfort and sleepiness (means per condition < 2) across participants and conditions (Table 2). An effect of condition on physical discomfort was found, indicating a higher discomfort at RS2/OM compared to two other conditions across participants $\left(X^{2}=8.064, \mathrm{p}=0.018\right.$; RS1: $z=-1.998, p=0.046 ; \mathrm{RS3}: z=$ $-2.092, p=0.036$ ) probably due to the longer recording for the second block. Sleepiness was also lower during RS3 compared to RS2/OM across participants $\left(X^{2}=7.225, p=\right.$ $0.027 ; z=2.982, p=0.003)$. Group comparisons showed that meditators reported lower emotional charge at RS1 and RS2/OM (respectively: $z=-3.080, p=0.004 ; z=-2.269, p=$ 0.023), as well as lower physical discomfort at RS2/OM and RS3 (respectively: $z=-2.159$, $p=0.037 ; z=-3.304, p=0.003)$ compared to non-meditators. No difference was highlighted between groups for sleepiness (all $z<0.632, p>0.606$ ). 
medRxiv preprint doi: https://doi.org/10.1101/2021.11.22.21266675; this version posted November 24, 2021. The copyright holder for this preprint (which was not certified by peer review) is the author/funder, who has granted medRxiv a license to display the preprint in perpetuity.

It is made available under a CC-BY-NC-ND 4.0 International license .
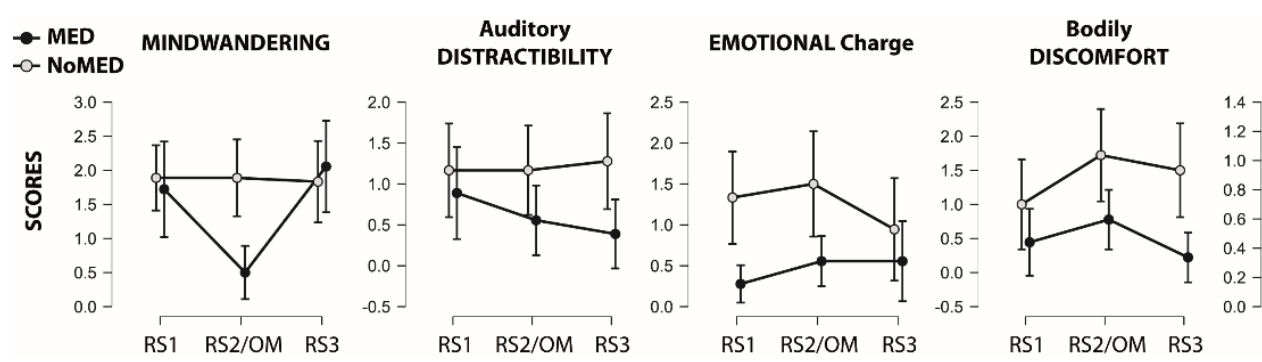

SLEEPINESS

Figure 4: Score related to phenomenological reports from participants. Error bars correspond to $95 \%$ confidence intervals. 
Table 2: State Analysis. Scores related to phenomenological reports and microstate temporal parameters according to groups and conditions.

RS1

RS2/OM

\begin{tabular}{|c|c|c|c|c|c|c|c|c|c|c|c|c|}
\hline & & & \\
\hline & \multicolumn{2}{|c|}{ noMED } & \multicolumn{2}{|c|}{ MED } & \multicolumn{2}{|c|}{ noMED } & \multicolumn{2}{|c|}{ MED } & \multicolumn{2}{|c|}{ noMED } & \multicolumn{2}{|c|}{ MED } \\
\hline & MEAN & SD & MEAN & SD & MEAN & SD & MEAN & SD & MEAN & SD & MEAN & SD \\
\hline \multicolumn{13}{|l|}{ PHENOMENOLOGY } \\
\hline Bodily discomfort & 1.00 & 1.33 & 0.44 & 0.98 & 1.72 & 1.36 & 0.78 & 0.88 & 1.50 & 1.38 & 0.22 & 0.73 \\
\hline Emotional charge & 1.33 & 1.34 & 0.28 & 0.46 & 1.50 & 1.30 & 0.56 & 0.61 & 0.94 & 1.26 & 0.56 & 0.98 \\
\hline Sleepiness & 0.78 & 1.11 & 0.50 & 0.71 & 0.89 & 1.02 & 0.72 & 0.58 & 0.39 & 0.78 & 0.44 & 0.62 \\
\hline Mind wandering & 1.89 & 0.96 & 1.72 & 1.41 & 1.89 & 1.13 & 0.50 & 0.79 & 1.83 & 1.20 & 2.06 & 1.35 \\
\hline Aud. distractibility & 1.17 & 1.15 & 0.89 & 1.13 & 1.17 & 1.10 & 0.56 & 0.86 & 1.28 & 1.18 & 0.39 & 0.85 \\
\hline \multicolumn{13}{|l|}{ MICROSTATE A } \\
\hline Occurrence & 2.93 & 0.80 & 2.88 & 0.93 & 2.54 & 0.60 & 2.69 & 0.83 & 2.59 & 0.77 & 2.39 & 0.85 \\
\hline Duration & 52.93 & 5.44 & 50.41 & 5.39 & 51.78 & 4.34 & 50.77 & 5.83 & 50.23 & 4.21 & 51.36 & 11.65 \\
\hline Coverage & 19.59 & 7.17 & 18.88 & 8.15 & 16.38 & 5.15 & 17.86 & 7.75 & 16.56 & 6.08 & 16.74 & 11.15 \\
\hline \multicolumn{13}{|l|}{ MICROSTATE B } \\
\hline Occurrence & 3.18 & 0.64 & 2.95 & 1.01 & 3.54 & 0.48 & 3.22 & 0.88 & 3.28 & 0.64 & 3.20 & 0.76 \\
\hline Duration & 56.41 & 10.95 & 53.40 & 9.74 & 60.28 & 10.05 & 55.27 & 10.61 & 58.50 & 15.75 & 50.09 & 15.98 \\
\hline Coverage & 24.21 & 12.5 & 21.39 & 11.88 & 28.03 & 9.83 & 24.01 & 12.31 & 25.99 & 13.29 & 25.92 & 14.84 \\
\hline \multicolumn{13}{|l|}{ MICROSTATE C } \\
\hline Occurrence & 2.69 & 0.70 & 3.56 & 0.75 & 2.47 & 0.69 & 3.45 & 0.84 & 2.88 & 0.73 & 3.36 & 0.86 \\
\hline Duration & 53.16 & 8.28 & 62.04 & 15.21 & 52.09 & 5.69 & 59.74 & 11.62 & 55.24 & 8.12 & 58.28 & 11.46 \\
\hline Coverage & 18.80 & 9.09 & 30.71 & 14.04 & 16.39 & 7.39 & 28.64 & 13.11 & 21.05 & 9.18 & 26.79 & 12.14 \\
\hline \multicolumn{13}{|l|}{ MICROSTATE D } \\
\hline Occurrence & 3.96 & 0.71 & 3.63 & 0.64 & 4.02 & 0.75 & 3.61 & 0.76 & 3.78 & 0.95 & 3.61 & 0.93 \\
\hline Duration & 68.87 & 10.42 & 59.62 & 9.32 & 70.24 & 12.43 & 60.31 & 9.93 & 67.99 & 18.09 & 60.82 & 10.75 \\
\hline Coverage & 37.40 & 11.07 & 29.02 & 8.47 & 39.20 & 12.77 & 29.49 & 10.25 & 36.40 & 15.42 & 30.55 & 12.41 \\
\hline
\end{tabular}




\section{Microstate analysis}

As explained above, temporal parameters can be compared only if microstates between conditions have the same topography (Bréchet et al., 2021; Grieder et al., 2016). Accordingly, we compared microstate temporal parameters related to RS1, OM, and RS3 within the meditator group only. Results are illustrated in Figure 5.

Microstate A. Repeated measure ANOVA revealed an effect of mental state on occurrence of microstate $A(F(2,34)=7.090, p=0.003)$. Post-hoc tests highlighted significant decrease between RS1 and RS3 ( $t=3.725, p=0.002)$ and between OM and RS3 ( $t=2.339, p=0.051$ ). No effect was found about duration and coverage (All $F<$ 1.130, $p>0.320)$. Interestingly, Spearman's rank correlation revealed that microstate A occurrence and coverage during RS3 (but not during RS1 and OM) were negatively correlated with FFMQ total score $(\rho(18)=-0.547, p=0.023 ; \rho(18)=-0.551, p=0.022$; Figure 6) in meditators (but not in non-meditators). This correlations was carried in particular by describing sub facet of FFMQ $(\rho(18)=-0.487, p=0.048 ; \rho(18)=-0.487, p=$ 0.048).

Microstate B. An effect of mental state was also found about microstate B duration $(F(2,34)=4.102, p=0.047)$ and coverage $(F(2,34)=4.696, p=0.032)$, as well a trend for occurrence $(F(2,34)=3.224, p=0.064)$. Post-hoc tests indicated significant increased duration ( $t=-2.845, p=0.022)$ and coverage $(t=-3.052, p=0.013)$ between RS1 and RS3, while the trend about occurrence suggested difference between RS1 and OM $(t=-2.793, p=0.037)$. Further, negative correlations were highlighted between temporal parameters of microstate B during RS3 and non-reactivity sub facet of FFMQ in meditators (occurrence: $\rho(18)=-0.548, p=0.023$; duration: $\rho(18)=-0.664, p=0.004$; coverage $\rho(18)=-0.658, p=0.004$; Figure 6 ). We also observed that coverage of microstate B was positively associated to observing sub facet during $\mathrm{OM}(\rho(18)=-0.507$, $p=0.038)$ in meditators. This effect was more specifically carried by occurrence $(\rho(18)$ $=-0.454, p=0.067)$ than duration $(\rho(18)=-0.261, p=0.313)$. 
Microstate "C ». As expected, an effect of mental state was highlighted on occurrence $(F(2,34)=3.691, p=0.035)$ and coverage $(F(2,34)=4.638, p=0.017)$ of microstate « $C$ ». A trend was also observed for duration $(F(2,34)=3.043, p=0.061)$. Post-hoc tests indicated that microstate " C 》 temporal parameters decrease in meditators between RS1 and RS3 (occurrence: $t=2.715, p=0.031$; duration: $t=2.447$, $p=0.059$; coverage: $t=3.044, p=0.013$ ). Correlations analysis showed that occurrence of microstate " C » was negatively correlated to non-reactivity sub facet of FFMQ whatever conditions, but more specifically during OM (RS1: $\rho(18)=-0.536, p=0.026$; OM: $\rho(18)=-0.660, p=0.006$; RS3: $\rho(18)=-0.528, p=0.029$; Figure 6).

Microstate $D$. No effect was found for temporal parameters of microstate $D$ (all $F<0.280, p>0.678)$. However, the coverage of microstate D during RS1 and RS2 were positively correlated to non-judgment subfacets of FFMQ in meditators (respectively: $\rho(18)=0.620, p=0.008 ; \rho(18)=0.564, p=0.018)$. More specifically, these correlations were respectively carried by duration during $\operatorname{RS} 1(\rho(18)=0.518, p=0.033)$ and occurrence during OM $(\rho(18)=0.559, p=0.020)$.

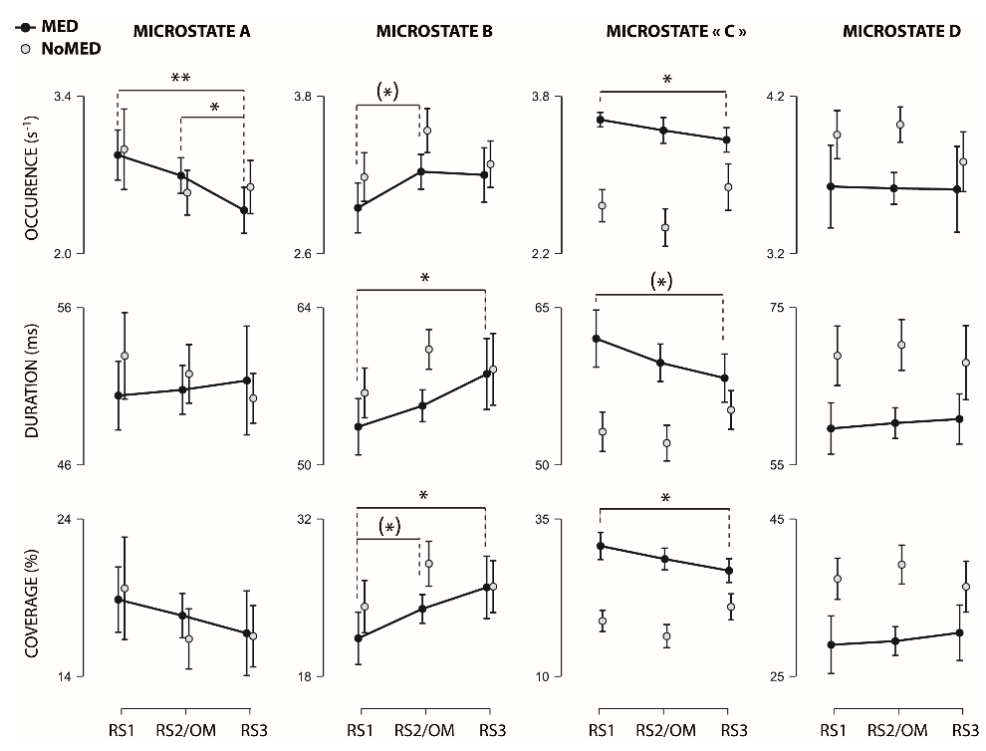

Figure 5: Microstate temporal parameters comparisons within meditators group. Non-meditators (white dots) were showed for information only, according to fact that the distinct topographies of microstate " $\mathrm{C}$ » in non-meditators did not allow us to consider their temporal parameters for statistical comparison (see methods). Error bars correspond to $95 \%$ confidence intervals. $\left({ }^{*}\right)$ corresponds to a statistical trend. * and ${ }^{* *}$ asterisks correspond to $p$-value related to post-hoc tests inferior to 0.05 and 0.01 respectively. 
A
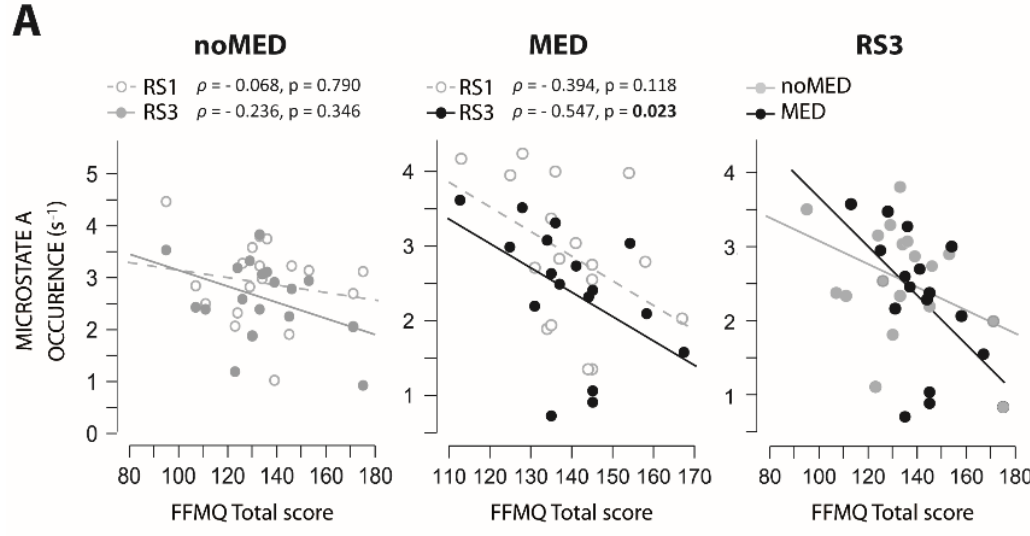

B
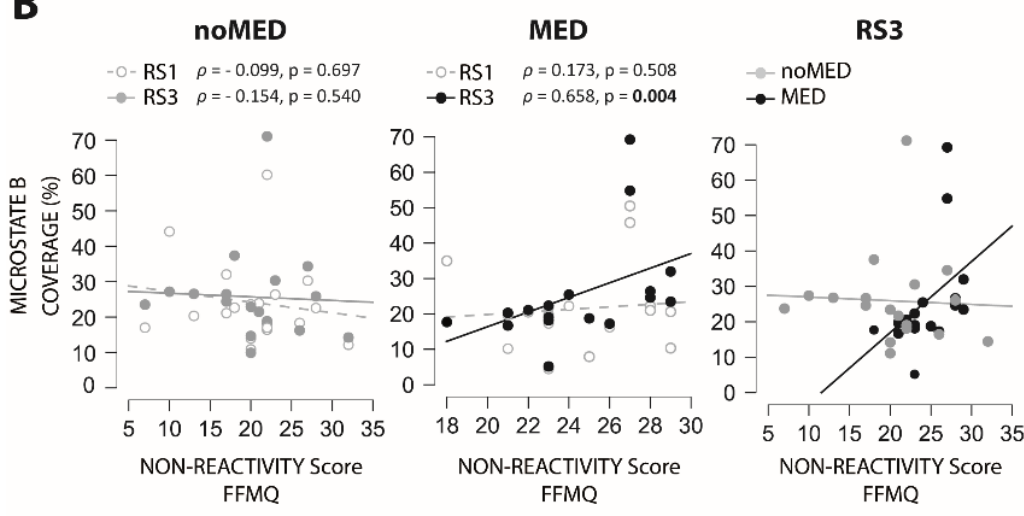

C

\section{RS1}

RS2

\section{RS3}

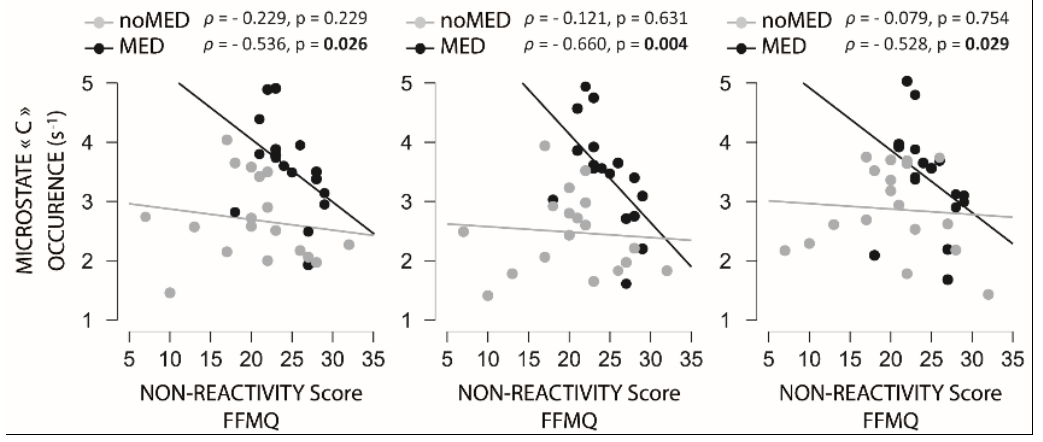

Figure 6: Significant results from correlations between mindfulness trait and the temporal parameters of microstate A, B, and " C " according to groups and conditions. (A) Microstate A occurrence was not correlated to FFMQ score in non-meditators at RS1 and RS3. Microstate A occurrence was negatively correlated to FFMQ score at RS3, but not at RS1 in meditators. Note also the decrease of microstate A occurrence at RS3 compared to RS1 in this group ( $t=3.725, p=0.002)$. (B) The coverage of microstate B was not correlated to the non-reactivity sub facet of FFMQ in non-meditators during RS1 nor RS3, while it was negatively correlated to FFMQ score at RS3 (but not at RS1) in meditators. Note also the increase of microstate B coverage during RS3 compared to RS1 in this group ( $t=-3.052, p=0.013)$, in particular for participants showing the high non-reactivity score. (C) The occurrence of microstate $C$ was correlated to FFMQ non-reactivity sub facet in meditators regardless of conditions. 


\section{Correlation analysis}

Corroborating trait analysis, the duration and the coverage of microstate " C » were positively correlated to auditory distractibility during RS1 in non-meditators (occurrence: $\rho(18)=0.409, p=0.092$; duration: $\rho(18)=0.602, p=0.008$; coverage: $\rho(18)$ $=0.549, p=0.018$ ) and in lesser extend in meditators (occurrence: $\rho(18)=0.175, p=$ 0.487; duration: $\rho(18)=0.513, p=0.029$; coverage: $\rho(18)=0.417, p=0.085$; Figure 7). Temporal parameters of microstate « $\mathrm{C}$ » were also correlated negatively to emotional charge reported by non-meditators during RS2 (occurrence: $\rho(18)=-0.487, p=0.040$; duration: $\rho(18)=-0.449, p=0.062$; coverage: $\rho(18)=-0.486, p=0.041$ ). Meditators showed also a marginal association between microstate " $C$ " and emotional charge during RS2 (occurrence: $\rho(18)=-0.522, p=0.026$; duration: $\rho(18)=-0.266, p=0.286$; coverage: $\rho(18)=-0.325, p=0.188$; Figure 7). During RS3, temporal parameters of microstate « $C$ » were negatively correlated to mind wandering in meditator group only (occurrence: $\rho(18)=-0.606, p=0.008$; duration: $\rho(18)=-0.451, p=0.060$; coverage: $\rho(18)=-0.531, p=0.023 ;$ Figure 7).

Regarding other microstates, no association was found between phenomenological reports and temporal parameters in non-meditators. In meditator group, dynamics of microstate $B$ showed an inverse dynamic than microstate $C$ in regards to phenomenological reports. Indeed, temporal parameters of microstate $B$ were negatively correlated to auditory reactivity during RS1 (occurrence: $\rho(18)=-0.436$, $p=0.071$; duration: $\rho(18)=-0.474, p=0.047$; coverage: $\rho(18)=-0.502, p=0.034)$, and positively correlated to emotion charge during RS2 (occurrence : $\rho(18)=0.494, p=$ 0.037; duration : $\rho(18)=0.513, p=0.029$; coverage: $\rho(18)=0.553, p=0.017$ ). During RS3, duration and coverage of microstate A was correlated to auditory distractibility (occurrence: $\rho(18)=-0.324, p=0.189$; duration: $\rho(18)=-0.608, p=0.007$; coverage: $\rho(18)=-0.608, p=0.007)$ in this same group. 


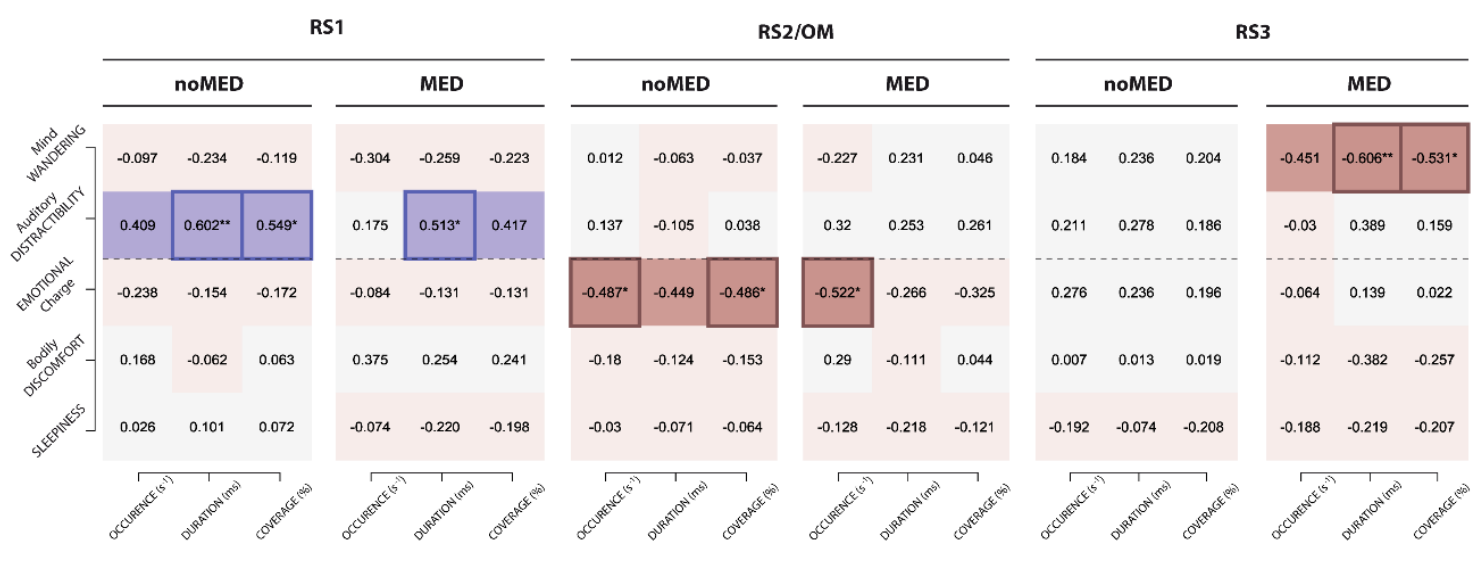

Figure 7: Correlation matrix between temporal parameters of microstate « C » and phenomenological reports from participants, according to groups and conditions. Blue and red colors correspond to positive and negative correlations respectively. Trends and significant correlations are points out by marked colors and squares respectively.

\section{Source localization analysis}

As illustrated in Figure 8, compared source analysis of microstate " C " topographies between groups at RS1 revealed higher activity in the right hemisphere including retrosplenial cortex (BA30: 28.3, -46.6, 9.4), PCC (BA31: 19.1, -65.1, 16.9), and a part of cuneus (BA18: 19.2, -67.1, 15.8) in meditators compared to non-meditators. In contrast, we found a higher activity of a left hemisphere area peaking in the superior temporal gyrus (BA22: $-50.8,14.4,-0.9$ ) in non-meditators compared to meditators (Figure 8). At RS2, while specific activities was restricted to right cerebellum (culmen: 10.1, -63.3, 9.5; declive: 10.3, -71.5, 17.3) and marginally in bilateral cuneus (BA18 L: 10.1, -78.1, 23.1; R: 11, -86.6, 14.1) in meditators, microstate « C " map in nonmeditators was characterized by distributed nodes activities in supramarginal gyrus (BA40: -39.1, -51.7, 34.6), ventral premotor cortex (BA6: -32.2, 3.4, 23.0) of left hemisphere, as well as nodes in dorsal premotor cortex (BA6: 36.9, -6.3, 48.5) and dIPFC (BA9: 36.4, 3.7, 31.6) in right hemisphere. At RS3, no significant generators activities were highlighted between groups except a marginal higher contribution in the left hemisphere of a localized fontal node (BA8: -21.7, 20.5, 32.6) in non-meditators (Figure 8). 
medRxiv preprint doi: https://doi.org/10.1101/2021.11.22.21266675; this version posted November 24, 2021. The copyright holder for this preprint (which was not certified by peer review) is the author/funder, who has granted medRxiv a license to display the preprint in perpetuity.

It is made available under a CC-BY-NC-ND 4.0 International license .

According to the high correlation of microstate « $C$ » maps between groups at RS3 (Figure 1), we took RS3 as standard to further compared generators underlying maps at RS1 and RS2 within the non-meditators group (Figure 8). Compared to RS3, microstate « $C$ » generators at RS1 were characterized by higher activity of thalamus (pulvinar: 5.4, -36.2, 9.6), ventral ACC (BA24: 16.2, -6.0, 47.8) and insula $(25.8,26.0,15.7$ ) in right hemisphere, as well as lower activity of left dorsal ACC (BA32: -14.1, 31.8, 13.8) and parts of cuneus bilaterally distributed (BA19 L: -28.2, -78.8, 24.1; BA18 R: 19.2, $68.1,15.7)$. Concerning RS2, comparison with RS3 within non-meditators showed similar generators of microstate « $\mathrm{C}$ » map than those highlighted by group comparison at RS2. Indeed, microstate " C " map at RS2 was characterized by widespread activities in supramarginal gyrus (BA40 L: -39.1, -51.7, 43.6) and ventral premotor cortex (BA6: -42.2, 1.4, 29.2) and ventral PCC (BA23: -9.5, -36.7, 18.7) in left hemisphere, as well as supramarginal gyrus (BA40 R: 47.8, -36.7, 27.2), angular gyrus (BA39: 55.1, -53.5, 14.9) and dorsal premotor cortex (BA6: 27.1, -7.4, 49.3) in right hemisphere. In contrast, RS3 showed higher activity in left cuneus (BA18: -18.1, -79.6, 24.8) and left caudate (body: $12.3,6.0,5.1$ ) compared to RS2 (Figure 8).

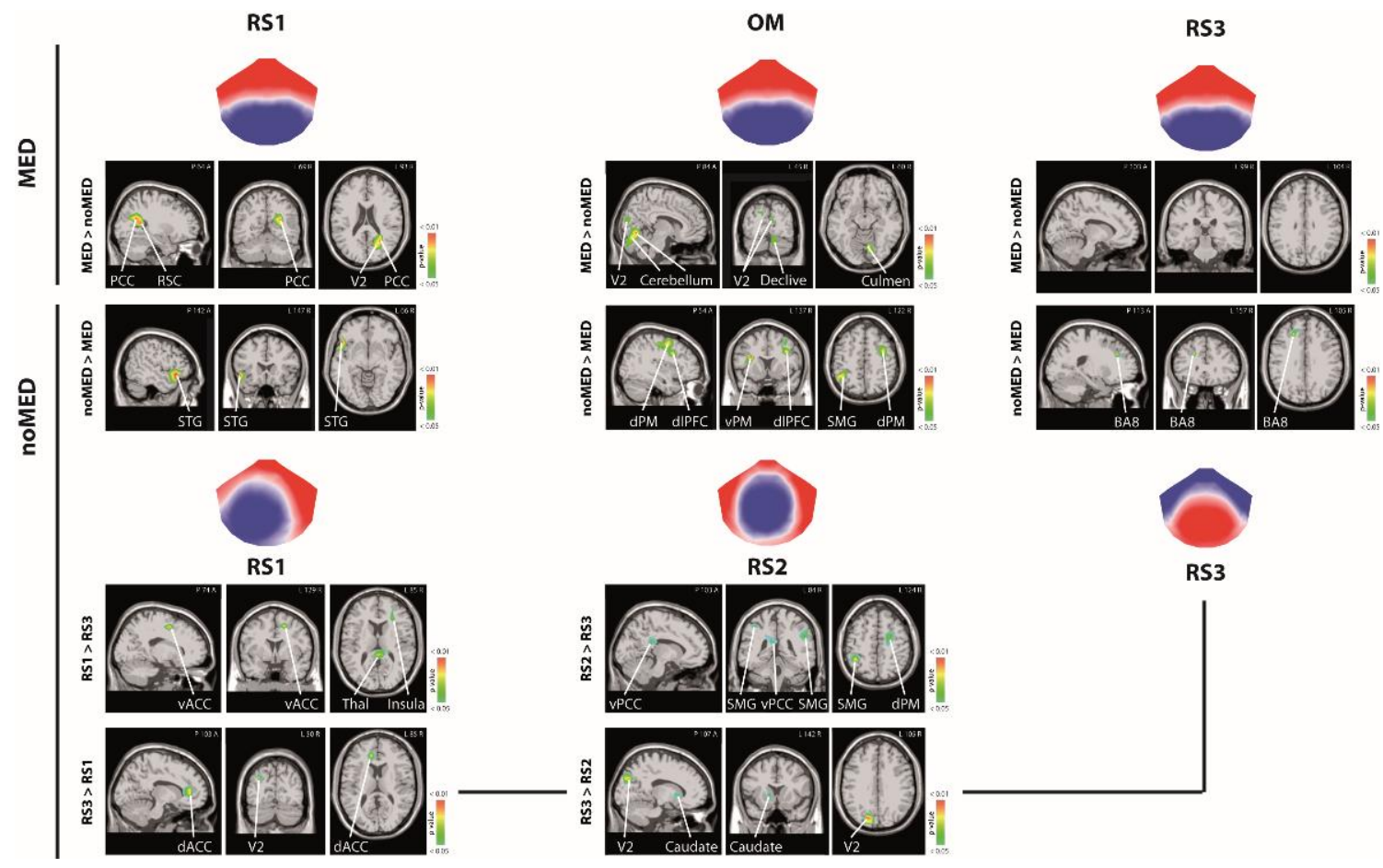


medRxiv preprint doi: https://doi.org/10.1101/2021.11.22.21266675; this version posted November 24, 2021. The copyright holder for this preprint (which was not certified by peer review) is the author/funder, who has granted medRxiv a license to display the preprint in perpetuity.

It is made available under a CC-BY-NC-ND 4.0 International license .

Figure 8: Source comparisons of the different microstate maps labeled as « $C$ " between groups and conditions. According to the high correlation of microstate « C » maps between groups at RS3, we took RS3 as standard to compared generators underlying maps at RS1 and RS2 within the non-meditators group. d/vACC: dorsal/ventral anterior cingulate cortex, PCC: posterior cingulate cortex; dIPFC: dorsolateral prefrontal cortex; d/vPM: dorsal/ventral premotor cortex; RSC: retrosplenial cortex; STG: supramarginal gyrus; V2: secondary visual cortex; BA8: Broadmann area 8, a part of frontal cortex including frontal eyes fields.

\section{DISCUSSION}

Regarding our research hypothesis, we found that temporal parameters of microstate $\mathrm{C}$ were lower in meditators compared to non-meditators at rest before meditation, but also decrease within the meditator group after OM. Moreover, the microstate $\mathrm{C}$ occurrence was correlated to the non-reactivity sub facet of FFMQ regardless of conditions. Topographic dissimilarities of microstates $C$ were revealed between groups, but also within the non-meditator group according to conditions, that were underpinned by differences at the generator-wide. Unexpectedly, we also observed an increase of microstate $\mathrm{B}$ temporal parameters during and after $\mathrm{OM}$, as well as a decrease of microstate $\mathrm{A}$ occurrence after $\mathrm{OM}$ in the meditator group. These results and their relations with phenomenal reports from participants are discussed below.

\section{Mindfulness trait modulates microstate C}

Trait analysis revealed lower duration, occurrence, and coverage of microstate $\mathrm{C}$ in meditators than non-meditators during the first 8-min resting-state recording. Considering BOLD correlates of microstate C previously reported (Britz et al., 2010), the positive association between the microstate $\mathrm{C}$ duration and distractibility reports from participants of both groups suggested that microstate $C$ reflects the activity of the SN. Accordingly, lower temporal parameters of microstate $\mathrm{C}$ would reflect the lower activity of SN evoked by auditory stimuli at rest in meditators compared to non-meditators. 
Further, negative correlations of observing sub facet of $\mathrm{FFMQ}^{2}$ with both the distractibility reports and the microstate $\mathrm{C}$ duration across participants seemed to confirm that relation between mindfulness trait and duration of microstate $C$ is mediated by the SN activity.

Interestingly, state analysis showed two different microstates C topographies according to groups during these first 8-min at rest, which are both correlated with distractibility reports by participants. We found that the microstate C topography related to the meditators group was characterized by higher contribution in the posterior cingulate cortex and lower activity of the right superior temporal gyrus (BA22, related to non-verbal sound processing). In contrast, the topography identified in nonmeditators was characterized by ventral anterior cingulate cortex (ACC), insula, and thalamus which are three major nodes of the SN (Seeley, 2019). These results are consistent with Custo et al. (2017) highlighting that the microstate C could collapse two microstates ( $C$ and $\mathrm{F}$ in their study): one related to the more posterior part of the $\mathrm{DMN}$, the other related to the SN. It has been further suggested that these two microstates reflect anti-correlated networks activities (Zanesco et al., 2021a).

\section{Mindfulness stabilize microstate C topography}

These two distinct microstates topography are also in line with report of Bréchet et al. (2021) showing that 6-week meditation training leads to change in the microstate topography identification at rest. In our case, however, $k$-means clustering identified also distinct topographies between groups from RS2/OM recording, that could reflect an effect of OM on microstate topography. Nevertheless, topographies related to microstate $\mathrm{C}$ remained stable across conditions in meditators while those of nonmeditators were surprisingly distinct across conditions.

Considering the higher emotional charge reported by non-meditators at RS1 and RS2, it may be possible that emotions in this group affected k-means clustering

\footnotetext{
${ }^{2}$ Observing sub facet of FFMQ refer to noticing or attends to internal and external experiences such as sensations, cognitions, emotions, sights, sounds, and smells (Baer et al., 2008)
} 
identification of microstate $\mathrm{C}$ which would related to networks involved in emotional salience integration (Britz et al., 2010). The correlation found between the microstate C occurrence and emotional charge in both groups suggested further that both distinct topographies at RS2 relied on emotional processes. Source analysis within nonmeditators also revealed that microstate C map at RS1 compared to RS3 was characterized by higher ventral ACC and lower dorsal ACC activities, classically recognized respectively as emotional and cognitive parts of the ACC (Bush et al., 2000). RS2 was characterized by widespread activities including ventral PCC and supramarginal gyrus also involved in various aspects of internally directed thought and self-generated emotions (Damasio et al., 2000; Kropf et al., 2019; Leech and Sharp, 2014).

In this emotional context, while the other microstate maps remained similar between groups, the lower coverage of the non-meditators' microstate $C$ (see Figure 6) could reflect higher variability in the temporal dynamics of brain activity in nonmeditators as argue by Panda et al. (2016). This higher variability could have induced different topographic identifications provided by fixed $k$-means clustering. In contrast, previous studies suggested that attentional control underlying meditation induced lower variability of brain networks dynamics through a decreased PCC connectivity in meditators (Panda et al., 2016). Considering also reports showing that mindfulness uncouples brain areas related to sensory, affective, and evaluative aspects of lived experience (Grant et al., 2011; Zorn et al., 2020), it is, therefore, possible that mindfulness leads brain networks to work more stably.

\section{Mindfulness state modulates microstate C}

The critical results from state analysis about the microstate $C$ concerned the decrease of its occurrence after OM compared to before. This result confirmed our hypothesis and corroborated the report of Faber et al. (2017), showing that transcending ${ }^{3}$ was marked by the lower occurrence of microstate $\mathrm{C}$ compared to mind

\footnotetext{
${ }^{3}$ Transcending is a mental state characterized by a deep detachment to mental content (Brandmeyer et al., 2019; Travis and Parim, 2017)
} 
wandering in expert meditators (Faber et al., 2017). It seems also critical to underline that the occurrence of microstate $\mathrm{C}$ during $\mathrm{OM}$ was correlated to the non-reactivity sub facet of FFMQ in meditators and was characterized at source level by a strong activity of the cerebellum (anterior and posterior part) compared to non-meditators.

In a recent study on children with attention-deficit/hyperactivity disorder, we previously suggested that the anterior part of the cerebellum contributed to automatic features of inhibition control integrating into its multiple internal representations the appropriate behavioral responses to stimuli (Zarka et al., 2021). Thus, according to the critical role of the cerebellum in sensorimotor control and learning (Cheron et al., 2013, 2016; De Zeeuw, 2021), this structure would also represent a major neural substrate of non-reactivity behavior (motor and cognitive inhibition provided by the cerebellar cortex) underlying mindfulness meditation. But, beyond this sensorimotor aspect assumed by the anterior part of the cerebellum, the role of its posterior part in affective and (non-motor) cognitive functions is also well-established now (Argyropoulos et al., 2020; Stoodley and Schmahmann, 2018).

According to Schmahmann (2019), the cerebellum serves as an oscillation dampener smoothing out motor but also emotional and cognitive performance. It acts as a controller of neural functions (including sensorimotor, emotional, and cognitive functions) using adaptive mechanisms based on internal models for the detection of errors, and may prevent/corrects errors to maintain behavior around the intended homeostatic baseline. Thus, the cerebellum modulates behaviors comparing the consequences of (non-)actions with the intended outcome, matching reality with perceived reality. In other words, it represents the ideal candidate to explain cognitive defusion mechanisms enabled by non-reactive monitoring underlying mindfulness meditation (Zorn et al., 2021) as well as their strong network-wide effects through the integrated network that it constitutes with basal ganglia and cerebral cortex (Bostan and Strick, 2018; Santarnecchi et al., 2021). 


\section{Mindfulness effects on microstate B and A}

Contrasting with the absence of results for the microstate $D$, our data indicated a longer microstate B after OM than before in meditators. Further, the duration of microstate $B$ after the meditation was positively correlated to the non-reactivity sub facet of FFMQ. We also observed that microstate $B$ tends to be more frequent during the OM compared to rest. While unexpected, this may reflect the working memory processes underlying $\mathrm{OM}$, which are considered from origins as the core cognitive mechanism of mindfulness (Dreyfus, 2011) and may explain the diversity of benefits related to its training (Jha et al., 2019).

Finally, our data revealed that the occurrence of microstate $A$ at rest was negatively correlated to trait mindfulness across participants. This correlation was highlighted in particular for the non-judgment sub facet of FFMQ, suggesting that microstate $A$ occurrence was linked to a non-evaluative mental stance toward thoughts and feelings (Baer et al., 2008). Moreover, results from the state analysis showed that the occurrence of microstate $A$ at rest after $\mathrm{OM}$ was lower compared to before meditation and was also correlated to FFMQ in meditators. This correlation was highlighted more specifically for describing sub facet referring to the ability to labeling internal experiences with words (Baer et al., 2008). These results are in line with the association classically proposed between microstate $A$ and phonological processes (Britz et al., 2010). A recent report indicated that the occurrence of microstate $A$ would be positively correlated with depression severity (Damborská et al., 2019). These findings suggested that the occurrence of microstate A could reflect processes related to rumination, for which mindfulness aims to mitigate. Considering the well-established benefice of mindfulness meditation for depressive conditions and more generally for mental health-related quality of life (Goyal et al., 2014; Goldberg et al., 2018), these findings strongly encourage more research to assess the use of the microstate $A$ occurrence as a clinical biomarker to monitor depression course and mental well-being, as well as objectify the efficiency of mindfulness-based interventions to prevent depression relapse. 


\section{REFERENCES}

Argyropoulos, G.P.D., van Dun, K., Adamaszek, M., Leggio, M., Manto, M., Masciullo, M., Molinari, M., Stoodley, C.J., Van Overwalle, F., Ivry, R.B., Schmahmann, J.D., 2020. The Cerebellar Cognitive Affective/Schmahmann Syndrome: a Task Force Paper. Cerebellum Lond. Engl. 19, 102-125. https://doi.org/10.1007/s12311-019-01068-8

Baer, R.A., Smith, G.T., Hopkins, J., Krietemeyer, J., Toney, L., 2006. Using self-report assessment methods to explore facets of mindfulness. Assessment 13, 27-45. https://doi.org/10.1177/1073191105283504

Baer, R.A., Smith, G.T., Lykins, E., Button, D., Krietemeyer, J., Sauer, S., Walsh, E., Duggan, D., Williams, J.M.G., 2008. Construct validity of the five facet mindfulness questionnaire in meditating and nonmeditating samples. Assessment 15, 329-342. https://doi.org/10.1177/1073191107313003

Batchelor, M., 2011. Meditation and mindfulness. Contemp. Buddhism 12, 157-164. https://doi.org/10.1080/14639947.2011.564832

Benjamini, Y., Hochberg, Y., 1995. Controlling the False Discovery Rate: A Practical and Powerful Approach to Multiple Testing. J. R. Stat. Soc. Ser. B Methodol. 57, 289-300. https://doi.org/10.1111/j.2517-6161.1995.tb02031.x

Bilevicius, E., Smith, S.D., Kornelsen, J., 2018. Resting-State Network Functional Connectivity Patterns Associated with the Mindful Attention Awareness Scale. Brain Connect. 8, 4048. https://doi.org/10.1089/brain.2017.0520

Bishop, S.R., Lau, M., Shapiro, S., Carlson, L., Anderson, N.D., Carmody, J., Segal, Z.V., Abbey, S., Speca, M., Velting, D., Devins, G., 2004. Mindfulness: A Proposed Operational Definition. Clin. Psychol. Sci. Pract. 11, 230-241. https://doi.org/10.1093/clipsy.bph077

Bodhi, B., 2011. What does mindfulness really mean? A canonical perspective. Contemp. Buddhism 12, 19-39. https://doi.org/10.1080/14639947.2011.564813

Bostan, A.C., Strick, P.L., 2018. The basal ganglia and the cerebellum: nodes in an integrated network. Nat. Rev. Neurosci. 19, 338-350. https://doi.org/10.1038/s41583-018-0002-7

Brandmeyer, T., Delorme, A., 2018. Reduced mind wandering in experienced meditators and associated EEG correlates. Exp. Brain Res. 236, 2519-2528. https://doi.org/10.1007/s00221-016-4811-5

Bréchet, L., Brunet, D., Birot, G., Gruetter, R., Michel, C.M., Jorge, J., 2019. Capturing the spatiotemporal dynamics of self-generated, task-initiated thoughts with EEG and fMRI. Neurolmage 194, 82-92. https://doi.org/10.1016/j.neuroimage.2019.03.029

Bréchet, L., Ziegler, D.A., Simon, A.J., Brunet, D., Gazzaley, A., Michel, C.M., 2021. Reconfiguration of Electroencephalography Microstate Networks after BreathFocused, Digital Meditation Training. Brain Connect. 11, 146-155. https://doi.org/10.1089/brain.2020.0848

Brewer, J.A., Worhunsky, P.D., Gray, J.R., Tang, Y.-Y., Weber, J., Kober, H., 2011. Meditation experience is associated with differences in default mode network activity and connectivity. Proc. Natl. Acad. Sci. 108, 20254-20259. https://doi.org/10.1073/pnas.1112029108

Britz, J., Van De Ville, D., Michel, C.M., 2010. BOLD correlates of EEG topography reveal rapid resting-state network dynamics. Neurolmage 52, 1162-1170. https://doi.org/10.1016/j.neuroimage.2010.02.052 
Brodbeck, V., Kuhn, A., von Wegner, F., Morzelewski, A., Tagliazucchi, E., Borisov, S., Michel, C.M., Laufs, H., 2012. EEG microstates of wakefulness and NREM sleep. Neurolmage 62, 2129-2139. https://doi.org/10.1016/j.neuroimage.2012.05.060

Brown, K.W., Ryan, R.M., 2003. The benefits of being present: mindfulness and its role in psychological well-being. J. Pers. Soc. Psychol. 84, 822-848. https://doi.org/10.1037/0022-3514.84.4.822

Brunet, D., Murray, M.M., Michel, C.M., 2011. Spatiotemporal analysis of multichannel EEG: CARTOOL. Comput. Intell. Neurosci. 2011. https://doi.org/10.1155/2011/813870

Bush, null, Luu, null, Posner, null, 2000. Cognitive and emotional influences in anterior cingulate cortex. Trends Cogn. Sci. 4, 215-222. https://doi.org/10.1016/s13646613(00)01483-2

Buysse, D.J., Reynolds, C.F., Monk, T.H., Berman, S.R., Kupfer, D.J., 1989. The Pittsburgh Sleep Quality Index: a new instrument for psychiatric practice and research. Psychiatry Res. 28, 193-213. https://doi.org/10.1016/0165-1781(89)90047-4

Carmody, J., Baer, R.A., 2008. Relationships between mindfulness practice and levels of mindfulness, medical and psychological symptoms and well-being in a mindfulnessbased stress reduction program. J. Behav. Med. 31, 23-33. https://doi.org/10.1007/s10865-007-9130-7

Cebolla, A.M., Palmero-Soler, E., Dan, B., Cheron, G., 2011. Frontal phasic and oscillatory generators of the N30 somatosensory evoked potential. Neurolmage 54, 1297-1306. https://doi.org/10.1016/j.neuroimage.2010.08.060

Cebolla, A.-M., Palmero-Soler, E., Leroy, A., Cheron, G., 2017. EEG Spectral Generators Involved in Motor Imagery: A swLORETA Study. Front. Psychol. 8, 2133. https://doi.org/10.3389/fpsyg.2017.02133

Cebolla, A.M., Petieau, M., Dan, B., Balazs, L., Mclntyre, J., Cheron, G., 2016. “Cerebellar contribution to visuo-attentional alpha rhythm: insights from weightlessness." Sci. Rep. 6, 1-10. https://doi.org/10.1038/srep37824

Cheron, G., Dan, B., Márquez-Ruiz, J., 2013. Translational approach to behavioral learning: lessons from cerebellar plasticity. Neural Plast. 2013, 853654. https://doi.org/10.1155/2013/853654

Cheron, G., Márquez-Ruiz, J., Dan, B., 2016. Oscillations, Timing, Plasticity, and Learning in the Cerebellum. Cerebellum Lond. Engl. 15, 122-138. https://doi.org/10.1007/s12311015-0665-9

Cohen, S., Kamarck, T., Mermelstein, R., 1983. A Global Measure of Perceived Stress. J. Health Soc. Behav. 24, 385-396. https://doi.org/10.2307/2136404

Collins, D.L., Neelin, P., Peters, T.M., Evans, A.C., 1994. Automatic 3D intersubject registration of MR volumetric data in standardized Talairach space. J. Comput. Assist. Tomogr. 18, 192-205.

Crane, R.S., Brewer, J., Feldman, C., Kabat-Zinn, J., Santorelli, S., Williams, J.M.G., Kuyken, W., 2017. What defines mindfulness-based programs? The warp and the weft. Psychol. Med. 47, 990-999. https://doi.org/10.1017/S0033291716003317

Crane, R.S., Eames, C., Kuyken, W., Hastings, R.P., Williams, J.M.G., Bartley, T., Evans, A., Silverton, S., Soulsby, J.G., Surawy, C., 2013. Development and validation of the mindfulness-based interventions - teaching assessment criteria (MBI:TAC). Assessment 20, 681-688. https://doi.org/10.1177/1073191113490790

Creswell, J.D., Taren, A.A., Lindsay, E.K., Greco, C.M., Gianaros, P.J., Fairgrieve, A., Marsland, A.L., Brown, K.W., Way, B.M., Rosen, R.K., Ferris, J.L., 2016. Alterations in Resting-State Functional Connectivity Link Mindfulness Meditation With Reduced Interleukin-6: A 
Randomized Controlled Trial. Biol. Psychiatry 80, 53-61. https://doi.org/10.1016/j.biopsych.2016.01.008

Custo, A., Van De Ville, D., Wells, W.M., Tomescu, M.I., Brunet, D., Michel, C.M., 2017. Electroencephalographic Resting-State Networks: Source Localization of Microstates. Brain Connect. 7, 671-682. https://doi.org/10.1089/brain.2016.0476

Damasio, A.R., Grabowski, T.J., Bechara, A., Damasio, H., Ponto, L.L.B., Parvizi, J., Hichwa, R.D., 2000. Subcortical and cortical brain activity during the feeling of self-generated emotions. Nat. Neurosci. 3, 1049-1056. https://doi.org/10.1038/79871

Damborská, A., Tomescu, M.I., Honzírková, E., Barteček, R., Hořínková, J., Fedorová, S., Ondruš, Š., Michel, C.M., 2019. EEG Resting-State Large-Scale Brain Network Dynamics Are Related to Depressive Symptoms. Front. Psychiatry 10, 548.

https://doi.org/10.3389/fpsyt.2019.00548

de Bruin, E.I., Topper, M., Muskens, J.G.A.M., Bögels, S.M., Kamphuis, J.H., 2012. Psychometric Properties of the Five Facets Mindfulness Questionnaire (FFMQ) in a Meditating and a Non-meditating Sample. Assessment 19, 187-197. https://doi.org/10.1177/1073191112446654

De Zeeuw, C.I., 2021. Bidirectional learning in upbound and downbound microzones of the cerebellum. Nat. Rev. Neurosci. 22, 92-110. https://doi.org/10.1038/s41583-02000392-x

Delorme, A., Makeig, S., 2004. EEGLAB: An open source toolbox for analysis of single-trial EEG dynamics including independent component analysis. J. Neurosci. Methods 134, 9-21. https://doi.org/10.1016/j.jneumeth.2003.10.009

Dresse, A., 2005. [The Ethics Committee meeting in Belgium May 7, 2004, on human experimentation]. Bull. Mem. Acad. R. Med. Belg. 160, 224-230; discussion 230-231.

Dreyfus, G., 2011. Is mindfulness present-centred and non-judgmental? A discussion of the cognitive dimensions of mindfulness. Contemp. Buddhism 12, 41-54. https://doi.org/10.1080/14639947.2011.564815

Evans, A.C., Collins, D.L., Mills, S.R., Brown, E.D., Kelly, R.L., Peters, T.M., 1993. 3D statistical neuroanatomical models from 305 MRI volumes, in: 1993 IEEE Conference Record Nuclear Science Symposium and Medical Imaging Conference. Presented the 1993 IEEE Conference Record Nuclear Science Symposium and Medical Imaging Conference, IEEE, San Francisco, CA, USA, pp. 1813-1817. https://doi.org/10.1109/NSSMIC.1993.373602

Faber, P.L., Travis, F., Milz, P., Parim, N., 2017. EEG microstates during different phases of Transcendental Meditation practice. Cogn. Process. 18, 307-314. https://doi.org/10.1007/s10339-017-0812-y

Farb, N.A.S., Segal, Z.V., Mayberg, H., Bean, J., McKeon, D., Fatima, Z., Anderson, A.K., 2007. Attending to the present: mindfulness meditation reveals distinct neural modes of selfreference. Soc. Cogn. Affect. Neurosci. 2, 313-322. https://doi.org/10.1093/scan/nsm030

Forman, E.M., Herbert, J.D., Juarascio, A.S., Yeomans, P.D., Zebell, J.A., Goetter, E.M., Moitra, E., 2012. The Drexel defusion scale: A new measure of experiential distancing. J. Context. Behav. Sci. 1, 55-65. https://doi.org/10.1016/j.jcbs.2012.09.001

Geselowitz, D.B., 1967. On bioelectric potentials in an inhomogeneous volume conductor. Biophys. J. 7, 1-11. https://doi.org/10.1016/S0006-3495(67)86571-8

Goldberg, S.B., Del Re, A.C., Hoyt, W.T., Davis, J.M., 2014. The secret ingredient in mindfulness interventions? A case for practice quality over quantity. J. Couns. Psychol. 61, 491-497. https://doi.org/10.1037/cou0000032 
Goldberg, S.B., Tucker, R.P., Greene, P.A., Davidson, R.J., Wampold, B.E., Kearney, D.J., Simpson, T.L., 2018. Mindfulness-based interventions for psychiatric disorders: A systematic review and meta-analysis. Clin. Psychol. Rev. 59, 52-60. https://doi.org/10.1016/j.cpr.2017.10.011

Goyal, M., Singh, S., Sibinga, E.M.S., Gould, N.F., Rowland-Seymour, A., Sharma, R., Berger, Z., Sleicher, D., Maron, D.D., Shihab, H.M., Ranasinghe, P.D., Linn, S., Saha, S., Bass, E.B., Haythornthwaite, J.A., 2014. Meditation programs for psychological stress and wellbeing: a systematic review and meta-analysis. JAMA Intern. Med. 174, 357-368. https://doi.org/10.1001/jamainternmed.2013.13018

Grant, J.A., Courtemanche, J., Rainville, P., 2011. A non-elaborative mental stance and decoupling of executive and pain-related cortices predicts low pain sensitivity in Zen meditators. PAIN ${ }^{\circledR}$ 152, 150-156. https://doi.org/10.1016/j.pain.2010.10.006

Grieder, M., Koenig, T., Kinoshita, T., Utsunomiya, K., Wahlund, L.-O., Dierks, T., Nishida, K., 2016. Discovering EEG resting state alterations of semantic dementia. Clin.

Neurophysiol. Off. J. Int. Fed. Clin. Neurophysiol. 127, 2175-2181. https://doi.org/10.1016/j.clinph.2016.01.025

Hasenkamp, W., Barsalou, L.W., 2012. Effects of Meditation Experience on Functional Connectivity of Distributed Brain Networks. Front. Hum. Neurosci. 6. https://doi.org/10.3389/fnhum.2012.00038

Heeren, A., Douilliez, C., Peschard, V., Debrauwere, L., Philippot, P., 2011. Cross-cultural validity of the Five Facets Mindfulness Questionnaire: Adaptation and validation in a French-speaking sample. Eur. Rev. Appl. Psychol. 61, 147-151. https://doi.org/10.1016/j.erap.2011.02.001

Holmes, A.P., Blair, R.C., Watson, J.D., Ford, I., 1996. Nonparametric analysis of statistic images from functional mapping experiments. J. Cereb. Blood Flow Metab. Off. J. Int. Soc. Cereb. Blood Flow Metab. 16, 7-22. https://doi.org/10.1097/00004647-19960100000002

Hölzel, B.K., Hoge, E.A., Greve, D.N., Gard, T., Creswell, J.D., Brown, K.W., Barrett, L.F., Schwartz, C., Vaitl, D., Lazar, S.W., 2013. Neural mechanisms of symptom improvements in generalized anxiety disorder following mindfulness training. Neurolmage Clin. 2, 448-458. https://doi.org/10.1016/j.nicl.2013.03.011

Jha, A.P., Denkova, E., Zanesco, A.P., Witkin, J.E., Rooks, J., Rogers, S.L., 2019. Does mindfulness training help working memory "work" better? Curr. Opin. Psychol. 28, 273-278. https://doi.org/10.1016/j.copsyc.2019.02.012

Kabat-Zinn, J., 1990. Full catastrophe living: Using the wisdom of your body and mind to face stress, pain and illness. New York, NY: Delacorte.

Katayama, H., Gianotti, L.R.R., Isotani, T., Faber, P.L., Sasada, K., Kinoshita, T., Lehmann, D., 2007. Classes of multichannel EEG microstates in light and deep hypnotic conditions. Brain Topogr. 20, 7-14. https://doi.org/10.1007/s10548-007-0024-3

Khoury, B., Lecomte, T., Fortin, G., Masse, M., Therien, P., Bouchard, V., Chapleau, M.-A., Paquin, K., Hofmann, S.G., 2013. Mindfulness-based therapy: a comprehensive metaanalysis. Clin. Psychol. Rev. 33, 763-771. https://doi.org/10.1016/j.cpr.2013.05.005

Kilpatrick, L.A., Suyenobu, B.Y., Smith, S.R., Bueller, J.A., Goodman, T., Creswell, J.D., Tillisch, K., Mayer, E.A., Naliboff, B.D., 2011. Impact of Mindfulness-Based Stress Reduction training on intrinsic brain connectivity. Neurolmage 56, 290-298. https://doi.org/10.1016/j.neuroimage.2011.02.034

Koenig, T., Prichep, L., Lehmann, D., Sosa, P.V., Braeker, E., Kleinlogel, H., Isenhart, R., John, E.R., 2002. Millisecond by millisecond, year by year: normative EEG microstates and 
developmental stages. Neurolmage 16, 41-48.

https://doi.org/10.1006/nimg.2002.1070

Kral, T.R.A., Imhoff-Smith, T., Dean, D.C., Grupe, D., Adluru, N., Patsenko, E., Mumford, J.A., Goldman, R., Rosenkranz, M.A., Davidson, R.J., 2019. Mindfulness-Based Stress Reduction-related changes in posterior cingulate resting brain connectivity. Soc. Cogn. Affect. Neurosci. 14, 777-787. https://doi.org/10.1093/scan/nsz050

Kropf, E., Syan, S.K., Minuzzi, L., Frey, B.N., 2019. From anatomy to function: the role of the somatosensory cortex in emotional regulation. Rev. Bras. Psiquiatr. Sao Paulo Braz. 1999 41, 261-269. https://doi.org/10.1590/1516-4446-2018-0183

Krzanowski, W.J., Lai, Y.T., 1988. A Criterion for Determining the Number of Groups in a Data Set Using Sum-of-Squares Clustering. Biometrics 44, 23. https://doi.org/10.2307/2531893

Lancaster, J.L., Woldorff, M.G., Parsons, L.M., Liotti, M., Freitas, C.S., Rainey, L., Kochunov, P.V., Nickerson, D., Mikiten, S.A., Fox, P.T., 2000. Automated Talairach atlas labels for functional brain mapping. Hum. Brain Mapp. 10, 120-131. https://doi.org/10.1002/1097-0193(200007)10:3<120::aid-hbm30>3.0.co;2-8

Leech, R., Sharp, D.J., 2014. The role of the posterior cingulate cortex in cognition and disease. Brain 137, 12-32. https://doi.org/10.1093/brain/awt162

Lehmann, D., Ozaki, H., Pal, I., 1987. EEG alpha map series: brain micro-states by spaceoriented adaptive segmentation. Electroencephalogr. Clin. Neurophysiol. 67, 271-288. https://doi.org/10.1016/0013-4694(87)90025-3

Leroy, A., Cevallos, C., Cebolla, A.-M., Caharel, S., Dan, B., Cheron, G., 2017. Short-term EEG dynamics and neural generators evoked by navigational images. PloS One 12, e0178817. https://doi.org/10.1371/journal.pone.0178817

Lindquist, M.A., Mejia, A., 2015. Zen and the Art of Multiple Comparisons. Psychosom. Med. 77, 114-125. https://doi.org/10.1097/PSY.0000000000000148

Lutz, A., Jha, A.P., Dunne, J.D., Saron, C.D., 2015. Investigating the phenomenological matrix of mindfulness-related practices from a neurocognitive perspective. Am. Psychol. 70, 632-658. https://doi.org/10.1037/a0039585

Lutz, A., Slagter, H.A., Dunne, J.D., Davidson, R.J., 2008. Attention regulation and monitoring in meditation. Trends Cogn. Sci. 12, 163-169. https://doi.org/10.1016/j.tics.2008.01.005

Malika, C., Ghazzali, N., Boiteau, V., Niknafs, A., 2014. NbClust: an R package for determining the relevant number of clusters in a data Set. J Stat Softw 61, 1-36.

Michel, C.M., Koenig, T., 2018. EEG microstates as a tool for studying the temporal dynamics of whole-brain neuronal networks: A review. Neurolmage 180, 577-593. https://doi.org/10.1016/j.neuroimage.2017.11.062

Milligan, G.W., Cooper, M.C., 1985. An examination of procedures for determining the number of clusters in a data set. Psychometrika 50, 159-179. https://doi.org/10.1007/BF02294245

Milz, P., Faber, P.L., Lehmann, D., Koenig, T., Kochi, K., Pascual-Marqui, R.D., 2016. The functional significance of EEG microstates--Associations with modalities of thinking. Neurolmage 125, 643-656. https://doi.org/10.1016/j.neuroimage.2015.08.023

Nichols, T.E., Holmes, A.P., 2002. Nonparametric permutation tests for functional neuroimaging: a primer with examples. Hum. Brain Mapp. 15, 1-25.

Nielsen, M.G., Ørnbøl, E., Vestergaard, M., Bech, P., Larsen, F.B., Lasgaard, M., Christensen, K.S., 2016. The construct validity of the Perceived Stress Scale. J. Psychosom. Res. 84, 22-30. https://doi.org/10.1016/j.jpsychores.2016.03.009 
Palmero-Soler, E., Dolan, K., Hadamschek, V., Tass, P.A., 2007. swLORETA: a novel approach to robust source localization and synchronization tomography. Phys. Med. Biol. 52, 17831800. https://doi.org/10.1088/0031-9155/52/7/002

Panda, R., Bharath, R.D., Upadhyay, N., Mangalore, S., Chennu, S., Rao, S.L., 2016. Temporal Dynamics of the Default Mode Network Characterize Meditation-Induced Alterations in Consciousness. Front. Hum. Neurosci. 10, 372. https://doi.org/10.3389/fnhum.2016.00372

Parkinson, T.D., Kornelsen, J., Smith, S.D., 2019. Trait Mindfulness and Functional Connectivity in Cognitive and Attentional Resting State Networks. Front. Hum. Neurosci. 13, 112. https://doi.org/10.3389/fnhum.2019.00112

Pascual-Marqui, R.D., 2002. Standardized low-resolution brain electromagnetic tomography (sLORETA): technical details. Methods Find. Exp. Clin. Pharmacol. 24 Suppl D, 5-12.

Pascual-Marqui, R.D., Esslen, M., Kochi, K., Lehmann, D., 2002. Functional imaging with lowresolution brain electromagnetic tomography (LORETA): a review. Methods Find. Exp. Clin. Pharmacol. 24 Suppl C, 91-95.

Petitmengin, C., van Beek, M., Bitbol, M., Nissou, J.-M., Roepstorff, A., 2019. Studying the experience of meditation through Micro-phenomenology. Curr. Opin. Psychol. 28, 5459. https://doi.org/10.1016/j.copsyc.2018.10.009

Rieger, K., Diaz Hernandez, L., Baenninger, A., Koenig, T., 2016. 15 Years of Microstate Research in Schizophrenia - Where Are We? A Meta-Analysis. Front. Psychiatry 7, 22. https://doi.org/10.3389/fpsyt.2016.00022

Santarnecchi, E., Egiziano, E., D’Arista, S., Gardi, C., Romanella, S.M., Mencarelli, L., Rossi, S., Reda, M., Rossi, A., 2021. Mindfulness-based stress reduction training modulates striatal and cerebellar connectivity. J. Neurosci. Res. 99, 1236-1252. https://doi.org/10.1002/jnr.24798

Schmahmann, J.D., 2019. The cerebellum and cognition. Neurosci. Lett. 688, 62-75. https://doi.org/10.1016/j.neulet.2018.07.005

Seeley, W.W., 2019. The Salience Network: A Neural System for Perceiving and Responding to Homeostatic Demands. J. Neurosci. 39, 9878-9882. https://doi.org/10.1523/JNEUROSCI.1138-17.2019

Soler, J., Tejedor, R., Feliu-Soler, A., Pascual, J.C., Cebolla, A., Soriano, J., Alvarez, E., Perez, V., 2012. Psychometric proprieties of Spanish version of Mindful Attention Awareness Scale (MAAS). Actas Esp. Psiquiatr. 40, 19-26.

Stoodley, C.J., Schmahmann, J.D., 2018. Functional topography of the human cerebellum. Handb. Clin. Neurol. 154, 59-70. https://doi.org/10.1016/B978-0-444-63956-1.000047

Taren, A.A., Gianaros, P.J., Greco, C.M., Lindsay, E.K., Fairgrieve, A., Brown, K.W., Rosen, R.K., Ferris, J.L., Julson, E., Marsland, A.L., Creswell, J.D., 2017. Mindfulness Meditation Training and Executive Control Network Resting State Functional Connectivity: A Randomized Controlled Trial. Psychosom. Med. 79, 674-683. https://doi.org/10.1097/PSY.0000000000000466

Wagner, M., Fuchs, M., Kastner, J., 2004. Evaluation of sLORETA in the presence of noise and multiple sources. Brain Topogr. 16, 277-280.

Wang, X., Xu, M., Song, Y., Li, X., Zhen, Z., Yang, Z., Liu, J., 2014. The network property of the thalamus in the default mode network is correlated with trait mindfulness. Neuroscience 278, 291-301. https://doi.org/10.1016/j.neuroscience.2014.08.006 
World Medical Association Declaration of Helsinki: Ethical Principles for Medical Research Involving Human Subjects, 2013. . JAMA 310, 2191. https://doi.org/10.1001/jama.2013.281053

Zanesco, A.P., Denkova, E., Jha, A.P., 2021a. Self-reported Mind Wandering and Response Time Variability Differentiate Prestimulus Electroencephalogram Microstate Dynamics during a Sustained Attention Task. J. Cogn. Neurosci. 33, 28-45. https://doi.org/10.1162/jocn_a_01636

Zanesco, A.P., Skwara, A.C., King, B.G., Powers, C., Wineberg, K., Saron, C.D., 2021 b. Meditation training modulates brain electric microstates and felt states of awareness. Hum. Brain Mapp. 42, 3228-3252. https://doi.org/10.1002/hbm.25430

Zarka, D., Cebolla, A.M., Cevallos, C., Palmero-Soler, E., Dan, B., Cheron, G., 2021. Caudate and cerebellar involvement in altered $\mathrm{P} 2$ and $\mathrm{P} 3$ components of $\mathrm{GO} /$ NoGO evoked potentials in children with attention-deficit/hyperactivity disorder. Eur. J. Neurosci. 53, 3447-3462. https://doi.org/10.1111/ejn.15198

Zarka, D., Leroy, A., Cebolla, A., Cevallos, C., Palmero-Soler, E., Cheron, G., 2020. Neural generators involved in visual cue processing in children with attentiondeficit/hyperactivity disorder (ADHD). Eur. J. Neurosci. https://doi.org/10.1111/ejn.15040

Zhang, Z., Luh, W.-M., Duan, W., Zhou, G.D., Weinschenk, G., Anderson, A.K., Dai, W., 2021. Longitudinal effects of meditation on brain resting-state functional connectivity. Sci. Rep. 11, 11361. https://doi.org/10.1038/s41598-021-90729-y

Zigmond, A.S., Snaith, R.P., 1983. The Hospital Anxiety and Depression Scale. Acta Psychiatr. Scand. 67, 361-370. https://doi.org/10.1111/j.1600-0447.1983.tb09716.x

Zorn, J., Abdoun, O., Bouet, R., Lutz, A., 2020. Mindfulness meditation is related to sensoryaffective uncoupling of pain in trained novice and expert practitioners. Eur. J. Pain Lond. Engl. 24, 1301-1313. https://doi.org/10.1002/ejp.1576

Zorn, J., Abdoun, O., Sonié, S., Lutz, A., 2021. Cognitive Defusion Is a Core Cognitive Mechanism for the Sensory-Affective Uncoupling of Pain During Mindfulness Meditation. Psychosom. Med. 83, 566-578. https://doi.org/10.1097/PSY.0000000000000938 